\title{
Filosofía de la muerte (I)
}

En nuestro trabajo anterior, «La muerte y la teodicea» ', concluíamos que en la sociedad occidental avanzada se da un ocultamiento o disimulación. del hecho de la muerte, de tal modo, que la necesidad de reconquistar la propia muerte es un reto que pesa sobre el hombre actual, si quiere ser sujeto de su propia historia. Esta cuestión nos abría a una reflexión filosófica sobre la muerte, que ahora desarrollamos.

\section{A) INTRODUCCIÓN}

La realidad inorgánica se define formalmente como un ser en sí, es una entidad que básicamente ya es. Si tiene cierta potencialidad, ésta es mínima, y se actualiza en ciertas manifestaciones y alteraciones. En cambio, el organismo se define como un ser que actúa desde sí mismo y para sí mismo ${ }^{2}$. Y ese actuar no es sino un ir viviendo ${ }^{3}$. Por ello, mientras que la entidad inorgánica es básicamente acto, los seres orgánicos son, en gran medida, potencia de ser,

1. Cfr. M. Fdez. DEL RIESGo, La muerte y la teodicea, Estudio Agustiniano, Vol. XXIII. Fasc. I, Valladolid 1988, 119-156.

2. Aunque sin descartar cierto «altruismo», especialmente estudiado por la sociobiología. Cfr. FDEZ. DEL RiESG, La originalidad de la condición humana desde la perspectiva etológica y sociobiológica (II. La Ciudad de Dios. Real Monasterio de El Escorial. Vol. CXCIX. n. ${ }^{\circ}$, septiembre-diciembre 1986; 475 ss.

3. «Lo mismo tratándose del árbol que del animal, vivir es simplemente estar viviendo, es decir, ejecutando aquellos actos que brotan del viviente mismo y van orientados a su perfección interna. X. ZuBIRI, Naturaleza, Historia, Dios, Ed. Nacional, Madrid 1963, 162. Al respecto escribe también acertadamente M. HEIDEGGER: «La fruta no madura, por ejemplo, marcha hacia la madurez. Al madurar no se le va en manera alguna acumulando por fragmentos (...) lo que ella aún no es. Es ella misma quien se lleva a la madurez, y tal llevarse caracteriza su ser de fruta. Todo agregado imaginable sería incapaz de acabar con la no madurez de la fruta, si este ente no llegara a la madurez por sí mismo». M. HeIDEgGer, El Ser y el Tiempo, F.C.E. México 1968, 266. 
que se va actualizando conforme a las leyes de su especie. El organismo se desenvuelve llegando a ser lo que, en alguna medida, ya era en principio. Como dice J. Ferrater Mora, el animal básicamente hace la vida que le deja hacer su especie.

En cambio, el vivir, para el ser humano, viene a ser una dimensión ontológica que incluyendo lo biológico, lo rebasa. Y lo rebasa porque la vida humana no es simplemente un «ir viviendo», sino un «ir haciendo la propia vida». Esta peculiaridad del hombre J. Ferrater la llama «propiedad»: el hombre es un ser que se posee a sí mismo, o mejor que se va apropiando su vida. Ya no se trata de ir haciendo lo que dicta el saber de la especie, sino de ir autoconfigurándose gracias a la mediación de la libertad, la razón y el sentimiento creadores $^{4}$. El hombre tiene la capacidad de hacerse y deshacerse, de apropiarse en un intento de coincidir consigo mismo o enajenarse. Como decía Ortega y Gasset, el hombre busca ser feliz procurando que coincida la vida proyectada con la real y efectiva. Lo que busca es «encajar consigo mismo». Por ello, su modo de ser para sí mismo es mucho más radical que el del animal. No hay animal que tenga la capacidad de la enajenación. «Mientras lo orgánico puede ser de muchas maneras diferentes, pero sin dejar de ser nunca, la vida humana puede dejar de ser realmente ella misma» ${ }^{5}$.

Teniendo en cuenta todo esto, se comprende que las cesaciones material y orgánica, aunque quedan integradas en la muerte humana no la agotan. Esta última requiere algo más que el análisis de los fenómenos de desestructuración material y de desorganización y desintegración orgánicas. El hombre aparece dotado de inorganicidad (materialidad) y organicidad, pero transidas y sobredeterminadas por su individualidad personal. Como persona, el hombre es sujeto de un quehacer responsable, histórico y dramático, a través del cual alumbrará un sentido y conquistará su perfección o se malogrará ${ }^{6}$. Por ello la

4. En este sentido afirma M. Heidegger que el ser humano se caracteriza «porque en su ser le va este su ser». M. HeIDEgGER, o.c., 21. Y por ello su esencia la llamará «existencia» (Existenz): «sistere ex», «estar fuera de», es algo peculiar de quien tiene que ser, hacer su propia vida. El ser, en alguna medida, lo tiene delante, «como algo que construir y no como algo fijo en lo que reposar». R. RodRiguez GARCIA, Heidegger y la crisis de la época moderna, Cincel, Madrid 1987, 70 .

5. J. Ferrater Mora, El Ser y la Muerte, Aguilar, Madrid 1962, 176. El hombre es sujeto y objeto de su propia tarea, viniendo a ser un «riesgo abierto»: «Es posible que el experimento de su ser humano no salga, es posible que el hombre se deshumanice (...) se desacierte a sí mismo». M. THIELICKE, Vivir con la muerte, Herder, Barcelona 1984, 17.

6. El hombre mantiene una tensión dialéctica entre historia y naturaleza; «De este modo se ha logrado un compromiso entre la idea del ser humano como especie animal y la idea del mismo como un tipo de realidad que trasciende de alguna manera el ser animal y natural». J. FERRATER Mora-Priscilia CoHn, Ética aplicada, Alianza Universidad, Madrid 1981, 83. 
muerte humana «no acontece o sobreviene; es un acto que tiene lugar dentro de un drama»?

Profundizar en este carácter personal del acto del morir humano, nos exige desarrollar, aunque sea brevemente, una «analítica existencial».

\section{B) ANALÍTICA EXISTENCIAL}

Nuestro punto de partida será la autoconciencia. Es desde esta realidad humana desde donde vamos a abordar el tema de la muerte. La conciencia en la medida en que es realidad la aprehendemos como algo incondicional e indudable, aunque «encarnada en otra realidad y relacionada con otras realidades como ella» ${ }^{8}$. Esa conciencia es la propia vida humana. Como decía Ortega y Gasset, vivir es intimidad consigo y con las cosas ${ }^{9}$. Por ello, la vida consciente es una realidad radical que se conoce a sí misma conociendo la realidad que no es ella. Si profundizamos en este autoconocimiento, pondremos de relieve las estructuras existenciales del ser humano ${ }^{10}$.

\section{Personeidad (constitución óntica de la persona)}

La persona es algo irreductiblemente individual que descansa en sí. En este sentido es «suposito» (ser incomunicable o único ${ }^{11}$, «hipóstasis» (sustancia singular incomunicable), o más bien, «suposito racional» ${ }^{12}$. Además, y ya lo hemos indicado en la Introducción, se autoposee o «se es», en la medida en que conquista su ser desde dentro ${ }^{13}$. Y ello aunque ese poseerse necesite de la po-

7. J. Ferrater Mora, El Ser y la Muerte, o.c., 189.

8. J. Gómez Caffarena, Metafísica fundamental, Rev. de Occidente, Madrid 1969, 109.

9. «El atributo primero de esta realidad que llamamos «nuestra vida» es el existir por sí misma, el enterarse de sí, el ser transparente ante sí. Sólo por eso es indubitable ella y cuanto forma parte de ella -y sólo porque es la única indubitable es la realidad radical». J. ORTEGA Y GASSET, ¿Qué es la filosofía? Rev. de Occidente, Madrid 1966, 243.

10. Cfr. J. Gómez Caffarena, o.c., 124ss.

11. La antropología clásica indicaba la idea de unicidad con el término «incomunicabilidad».

12. Recordemos la definición de M.S. Boecio: Naturae rationalis individua substantia (Sustancia individual de naturaleza racional). Para Sto. Tomás de Aquino, la persona será lo subsistente de la naturaleza racional. Y X. Zubiri nos dirá que la sustantividad humana es un sistema que encierra dos subsistemas: cuerpo y psique. Cfr. X. ZuBIRI, El hombre y Dios, AlianzaSociedad de Estudios y Publicaciones, Madrid 1984, 39ss.

13. X. Zubiri afirma que la realidad humana es de suyo. La «suidad» viene a ser la razón formal de la personeidad; y ésta última es la forma de realidad del hombre: «La personeidad es inexorablemente el carácter de una realidad subsistente en la medida en que esta realidad es 'suya'». Y «... las modulaciones concretas que esa personeidad va adquiriendo es a lo que llamamos personalidad». X. ZuBIRI, o.c., 48 y 49. Por ello, el hombre, en razón de su personeidad es siempre el mismo, pero no en razón de su personalidad. Cf. X. ZuBIRI, o.c., 51. 
sesión del objeto como mediación. Al ser humano el ser le es dado como tarea, teniendo que apropiarse sus propias posibilidades. O como repite Heidegger, «El 'ser-ahí' es un ente al que en su ser le va este mismo» ${ }^{14}$. Y sólo es auténtico el que se escoge libremente y se hace él mismo coherentemente ${ }^{15}$. «Esta vida del existente con su intensidad y sus responsabilidades es lo que Kierkegaard llama la interioridad o la subjetividad ${ }^{16}$. En esta tarea de autoposesión, la persona humana se orienta mediante la referencia a valores que dibujan su vocación, y que le exigen compromiso y fidelidad. La existencia inauténtica es la fuga de la libertad, que Heidegger denominó el «mundo del ser», Sartre «la mala fe» y G. Marcel el «es natural».

Recapitulando podemos citar a E. Mounier: «Una persona es un ser espiritual constituido como tal por una forma de subsistencia y de independencia en su ser; mantiene esta subsistencia mediante su adhesión a una jerarquía de valores libremente adoptados, asimilados y vividos en un compromiso responsable y en una constante conversión ${ }^{17}$; unifica así toda su actividad en la libertad y desarrolla, por añadidura, a impulsos de actos creadores, la singularidad de su vocación» ${ }^{18}$.

Digamos también que el hombre frente a las cosas presenta, como dice Zubiri, «un modo de realidad ab-soluto», o más bien es un «absoluto relativo»: «Es absoluto porque es suyo frente a toda realidad posible, pero es relativo porque este modo de implantación absoluto es un carácter cobrado» ${ }^{19}$.

14. M. HEIDEGGER, o.c., 212.

15. Como afirma Laín comentando a Heidegger, existir auténticamente «es atenerse pura y totalmente al ser de la existencia propia, sólo al ser y a todo el ser de esa existencia, a la simple totalidad de su ser». P. LAin ENTRALGO, La espera y la esperanza, Rev. de Occidente, Madrid 1962, 289. Claro que en Heidegger esta expresión tiene especialmente un significado ontológico y no ético. En la existencia inauténtica no se puede revelar, iluminar el ser. Pero nosotros sí incluimos la dimensión ética en nuestra concepción.

16. E. Mounier, Introducción a los existencialismos, Guadarrama, Madrid 1967, 28.

17. La conversión es un continuo proceso de personalización en el que el individuo constantemente se transfigura hacia la realización de su vocación, que no es sino integración y unificación personal.

18. E. Mounier, Manifiesto al servicio del personalismo, Taurus, Madrid 1965, 75. Ya M. Scheler, antes que Mounier, destacó a la persona como descubridora y realizadora de valores y como apertura a la comunidad.

19. X. ZuBIRI, o.c., 52. En la modernidad apareció una reflexión sobre la persona que resaltó especialmente su dignidad. Kant consideró a la persona un valor absoluto, un fin en sí, que no podía ser tratado como puro medio: «... los seres racionales llámanse personas porque su naturaleza los distingue ya como fines en sí mismos, es decir, como algo que no puede ser usado meramente como medio, y, por tanto, limita en este sentido todo capricho (y es un objeto de respeto)». E. KANT, Fundamentación de la metafísica de las costumbres, Porrúa, México 1980, 44. 


\section{Mundaneidad}

El sujeto humano, como afirmó Heidegger, y ya hemos indicado, es «existencia», ante quien puede darse el objeto. En un primer momento, la actitud técnica y manipulativa interpreta al objeto como siéndole útil («estar a la mano» = «Zuhandensein»). $\mathrm{Y}$ en un segundo momento, la actitud teórica lo interpreta como estando ante él («estar ante mí», "estar ahí dado» = "Vorhandensein») ${ }^{20}$. La conciencia es pues autoconciencia mundana ${ }^{21}$. Claro que la autonomía de la conciencia respecto a los impulsos instintivos, le permite al hombre «decir no a las cosas» (Scheler, Zubiri), distanciándose de ellas, elevándolas a la dignidad de objetos, que puede percibir como realidades y vivir como valiosos. Por ello el hombre es «animal de realidades» ${ }^{22}$. El animal vive vinculado instintivamente a su entorno (Umwelt), mientras que el hombre se abre al mundo (Welt). El mundo viene a consistir en «un horizonte vasto que rompe por definición cualquier limitación precisa y elimina toda fijación, siendo por lo mismo más amplio que el espacio vital inmediato» ${ }^{23}$. Viene a representar el conjunto de las variopintas y plásticas posibilidades del ser humano.

\section{Corporeidad}

Esta mundaneidad del existente (junto a su temporalidad), implica también la corporeidad ${ }^{24}$. El yo humano es autoconciencia corporal. La conciencia es corpóreo-espiritual ${ }^{25}$. El hombre sin el cuerpo no tendría sensaciones,

20. Cfr. M. HeIdEgGER, o.c., 80 ss.

21. Como diría Heidegger, la mundaneidad es una estructura fundamental de la existencia. Implica el estado de referido de dicha existencia al mundo, familiaridad con el mundo, trato habitual y práxico-vital con las cosas. En este sentido, los entes intramundanos son primariamente útiles que componen un campo pragmático. Los útiles guardan relación unos con otros, y la totalidad se dibuja por su referencia al existente humano. (Cfr. M. HeIdegGer, o.c., 76 ss). Claro que en último término, Heidegger, con el término «mundo» alude a lo trascendente, a la apertura al ser que está implícita o es el transfondo de toda relación objetiva con los entes: «Mundo (...) no significa de ningún modo un ente ni un reino de entes, sino la apertura del ser». M. HEIDEGGER, Carta sobre el humanismo, Taurus, Madrid 1970, 49.

22. X. ZUBIRI, El hombre y Dios, o.c., 46. En este sentido estoy de acuerdo con Heidegger cuando concibe la esencia de la verdad como libertad, entendiendo por ella la condición trascendental de posibilidad del libre albedrío: el poder atenerse a las cosas sólo es posible si se es libre para la pura manifestabilidad de las mismas. Una apertura originaria de la existencia en que las cosas aparecen como tales, que «deja ser a los entes» y que permite elegir.

23. EMERICH CORETH, ¿Qué es el hombre?, Herder, Barcelona 1978, 99.

24. Como indica $X$. Zubiri, el cuerpo es «principio de actualidad en la realidad, el principio de estar presente en el cosmos y en el mundo». X. ZUBIRI, o.c., 40.

25. «El mundo existe para mí por y mediante el cuerpo, cuya presencia percibo con un espesor vivencial único, inextensible a las demás cosas que constituyen mi entorno de ser mundano». 
ni podría elaborarlas espiritualmente. Gracias a él, el mundo es para nosotros y nos relacionamos con los demás. «Mi cuerpo es para mí, escenario y campo de expresión de mi espíritu, límite con el no-yo y vehículo de relación» ${ }^{26}$. Pero más allá de su «dimensión instrumental» (si es que es correcta esta expresión), en cuanto vida personal, «somos cuerpos». Él es componente esencial de nuestro ser interior, porque éste también está dotado de una exterioridad ${ }^{27}$.

J.L. Ruiz DE LA PEÑA, El hombre y su muerte, Aldecoa, Burgos 1971, 293. Este carácter primario y unitario del propio cuerpo es también señalado por M. Scheler: El organismo nos es dado «... con independencia y anterioridad a cualquiera de las llamadas 'sensaciones orgánicas' separadas y antes que todas las peculiares percepciones exteriores de sí mismo, como un hecho fenoménico enteramente unitario y como sujeto de un 'encontrarse de tal o cual manera' (...) Y justamente este fenómeno radical, es el cuerpo, en el sentido más estricto de la palabra». M. SCHELER, Ética, T. II. Rev. de Occidente, Buenos Aires 1948, 192. En este sentido, el cuerpo es «un inmediato existencial» (G. Marcel).

26. A. BASAVE, Metafísica de la muerte. Ed. Augustinus, Madrid 1965, 105. El cuerpo es el escenario de la expresión y acción personales. La persona es el centro de un mundo que está detrás de los fragmentos sensoriales que nos llegan por los ojos y las manos. Cfr. M. ScHELER, Muerte y supervivencia, Goncourt, Buenos Aires 1979, 80-81. Piénsese en la riqueza del cuerpo como lenguaje: en la mirada, el beso, el llanto, la risa, los gestos corporales, la danza, la «mera presencia» o el «estar juntos» de los enamorados, etc., etc. Cfr. Dietrich von Hildebrand, Sobre la muerte, Ed. Encuentro, Madrid 1983, 39. E. Mounier, Oeuvres, V.III, Seuil, Paris 1962, 447.

27. La solidaridad que cada uno tiene,con su cuerpo es, en primer lugar, como dice von Hildebrand, algo fundado en la naturaleza del ser humano y que pertenece a la esfera moral. Así una agresión física nos hace «padecer»; pero la solidaridad del hombre con su cuerpo va más allá de esta afección o función psicobiológica. El apego que tenemos a nuestra realidad somática se traduce en el «gran valor» que posee para nosotros. Él y los sentidos representan un bien objetivo para nosotros. Cfr. D. von HILDEBRAND, o.c., 38.

En rigor no debo decir «tengo un cuerpo», pues la relación del yo con el cuerpo está más allá de la pura relación sujeto-objeto. Mi cuerpo, como diría G. Marcel, me es presente de un modo distinto de lo puramente objetivo. (De ahí esa vivencia primaria y unitaria del cuerpo a la que ya hemos aludido). Y ello, aunque en un momento determinado trascendamos nuestro cuerpo al intentar objetivarlo. Según G. Marcel, al decir «mi cuerpo es mío», no podemos pensar en un tipo de posesión como la que se da entre un perro y su amo. Esta última implica ciertas relaciones afectivas y sometimiento. La corporeidad es una «zona fronteriza entre el ser y el haber». G. MARCEL, Diario metafísico, Guadarrama, Madrid 1969, 102. Es cierto que tenemos que mantener a nuestro cuerpo, y que, en algún grado, nos obedece; pero el lazo que mantenemos con él no puede definirse propiamente hablando, «como una forma de posesión». Todo lo más, el término «tener» «en el sentido preciso de la palabra debe pensarse en analogía con la unidad sui generis que constituye mi cuerpo en tanto mío». G. MARCEL, El misterio del ser, Sudamericana, Buenos Aires 1964, 90. La concepción instrumental, en sentido estricto, es inapropiada para pensar en el cuerpo. Todo lo más podemos hablar del cuerpo como «principio de instrumentalidad»: «El cuerpo no es instrumento propio y verdadero, sino un principio de instrumentalidad (...) ya que todos los instrumentos se convierten en tales en virtud de un cuerpo que está en disposición de utilizarlos». Joseph GEVAERT, El problema del hombre, Sígueme, Salamanca 1984, 102. «Mi cuerpo es mío en tanto no lo contemplo, en tanto no coloco entre él y yo un intervalo, en tanto no es objeto para mí, sino que yo soy mi cuerpo». G. MARCEL, o.c., 90. «Decir 'mi cuerpo' es una cierta forma de decir 'yo mismo', es colocarme en una situación de independencia de toda relación instrumental». En este sentido mi cuerpo «no es asimilable a un objeto, a una cosa». G. MARCEL, o.c., 91-92. La relación con él no se deja objetivar del todo, y Marcel la denomina «mediación simpática». No pode- 
Por ser cuerpo, el hombre está también sujeto a las leyes de la naturaleza, de las que no puede emanciparse totalmente. Por esta razón, el cuerpo no deja de presentar cierta ambigüedad, pues, si por un lado, es presencia del ser humano, su mediación simbólica y campo expresivo, por otro no se deja de experimentar en muchas ocasiones como resistencia ${ }^{28}$. Todos al respecto experimentamos una «dimensión de pasividad», que se manifiesta «en tantos fracasos de nuestras acciones debido a la impotencia, a las pasiones, a la debilidad orgánica, etc» ${ }^{29}$. En este sentido el cuerpo también se nos aparece como límite ${ }^{30}$. Pero es sobre todo en la muerte cuando «el control sobre el cuerpo parece escaparse por completo al poder de la libertad» ${ }^{31}$. Una muerte que, teniendo en cuenta todo lo dicho, y más allá de la polémica sobre la inmortalidad no inmortalidad del alma, deberá afectar al núcleo más íntimo del ser personal ${ }^{32}$.

mos ni identificarnos ni distinguirnos totalmente de él. Somos más bien seres encarnados. Cfr. también J.L. RUIZ DE LA PEÑA, El hombre y su muerte, o.c., 293-294; G. MARCEL, Être et avoir, Aubier-Montaigne, Paris. Copyrigh, 1985, 126-127. Con todo esto queremos expresar, en último término, la unidad de la condición humana. Cosa que ya indicó Sto. Tomás de Aquino al resaltar nuestra unidad de ser y de naturaleza. Las clásicas categorías de «cuerpo» y «alma» no pueden entenderse como «dos seres con consistencia propia», sino como coprincipios ontológicos de una única realidad: el hombre. Para Sto. Tomás, el alma espiritual es la forma substancial responsable de todo el dinamismo del hombre (desde el vegetativo hasta el cognitivo). El hombre es el sujeto único de todas las acciones somáticas y espirituales. Esta unidad también hace comprensible que lo puramente orgánico y objetivo, que estudia la ciencia, no agote la corporeidad humana que participa en la realización personal. En este sentido, «la anatomía, el aparato sensomotor, la fisiología de los sentidos, los mecanismos pulsionales, etc., de los animales y del hombre son diversos, no gradual, sino esencialmente». J.L. RuIz DE LA PEÑA, Las nuevas antropologías, Sal Terrae, Santander 1983, 116. (Cfr. también X. Zubiri, o.c., 40). Añadamos a esto, que el espíritu (pensamiento autoconsciente y voluntad) tiene con respecto a la materia una dependencia extrínseca pero no intrínseca. $Y$ con ello no queremos adherirnos a ninguna clase de dualismo cartesiano, sino señalar que la persona humana «no puede ser comprendida solamente y en primer lugar como expresión o manifestación de la materia evolutiva». J. GeVAERT, o.c., 140. Digamos por último, que con el término espíritu, más allá de la inmaterialidad de las facultades volitiva e intelectiva, nos referimos a la unicidad no connumerable de la persona (absoluto relativo). Cuestión en la que todavía tenemos que insistir.

28. Con respecto a mi cuerpo «puedo prestarme a sus caprichos; puedo por el contrario, tratar de dominarlo. Puede ser mi tirano, pero también puedo convertirlo en mi esclavo». G. MARCEl, El misterio del ser, o.c., 87. Cfr. también V. JANKÉlÉVITCH, La mort, Flammarion, Paris 1977, 98, 113, 450. E.M. CioRAN, Ese maldito yo, Tusquets, Barcelona 1987, 82 y 143.

29. J. GeVAERT, O.C., 88.

30. Cfr. J. Gevaert, o.c., 103.

31. J. GERVAERT, o.c., 69. Cfr. también, 290.

32. La hipotética alma inmortal «desgajada» del cuerpo no podría realizar «todas las dimensiones especiales de la naturaleza humana»; ni «podría pretender el título de ser humano». J. GeVAert, o.c., 315 y 345. 


\section{Comunitariedad}

El yo no sólo se encuentra abierto y vinculado al mundo por el conocimiento y la acción, sino que también está estructuralmente en relación con los otros yo semejantes a él. Los otros están incluidos en el entramado de relaciones que constituyen el mundo, y los útiles también implican una relación a los otros. El mundo lo comparto, y en este sentido es un mundo público ${ }^{33}$. La persona «se rebela como esencialmente «colegiada», esencialmente referida a otros semejantes» ${ }^{34}$. Ello no significa negar la última y radical soledad que es el hombre. La individualidad irreductible del ser personal implica que, en último término, cada sujeto vive su intimidad de un modo intransferible. Pero es una soledad destinada, abocada esencialmente, al diálogo y la comunión ${ }^{35}$. En un sentido fundamental mi existencia se va a configurar como aceptación o rechazo del otro, revelándose con ello su carácter ético y personal. La persona es responsable de los otros ${ }^{36}$.

33. Cfr. R. Rodriguez García, Heidegger y la crisis de la época moderna, o.c., 101-102. Como diría Heidegger, «El 'ser-en' es 'ser con' otros». M. HeIDEGGER, El ser y el tiempo, o.c., 135. Nuestro autor habló de «mitsein» (ser con) y «mitdasein» (existir con). Yo estoy a priori abierto a los otros; es una relación que me constituye, y que se concreta en un trato específico, distinto del ocuparse de las cosas: es el «preocuparse por».

34. J. Gómez Caffarena, o.c., 127. Cfr. también O. González de Cardedal, la gloria del hombre, BAC, Madrid 1985, 7-8. 117.

35. «La persona es última soledad y primera compañía» O. GONZÁleZ DE CARDEDAL, o.c.,

36. Nótese además, que muchos de los problemas que más íntimamente nos afectan tienen una dimensión social o comunitaria: «Nacen específicamente en el espacio de los vínculos que nos unen con los demás hombres en el mundo: en el trabajo, en el dolor, en el gozo del amor y de la amistad, en la muerte del ser querido, en los conflictos que dividen a los hombres y en la esperanza que los une. El mismo sentido de la existencia y la posibilidad de realizar una auténtica libertad parecen depender en amplia medida de los demás». «... el mismo sentido de la existencia está ligado a la llamada del otro que quiere ser alguien delante de mí, o que me invita a ser alguien delante de él, en el amor y en la construcción de un mundo más humano». J. GeVAERT, o.c., 19 y 46.

Como nos recuerda Gevaert, hoy está superada la «egología» de una antropología que destaca al yo solitario volcado sobre el conocimiento científico del mundo. Una antropología que, arrancando de Descartes, se prolongó en el idealismo postkantiano, y que acabó con la absolutización del espíritu y la disolución del yo concreto y singular. Frente a esta línea de pensamiento, se destaca el pensamiento dialogal de M. Buber, E. Mounier y E. Levinas, que otorga una primacía especial a las relaciones con los demás cuando reflexiona sobre el hombre. Para M. Buber la relación yo-tú, como presencia inmediata, encuentro y diálogo, es el hecho primario de la antropología y la filosofía. (Cfr. M. Buber, Yo y tú, Buenos Aires 1956 y P. LAÍn ENTRALGo, Teoría y realidad del otro, T.I. Rev. de Occidente, Madrid 1968, 257-280). El personalismo de E. Mounier descentra al sujeto humano y lo sitúa en la perspectiva de apertura hacia los demás. El tú es una llamada a la tarea de realización personal que alumbra una comunidad. (Cfr. E. MouNIER, Manifiesto al servicio del personalismo, o.c. En la misma línea: M. NEDONCELLE, La réciprocité des consciences, essai sur la nature de la personne, Aubier, Paris 1962). También E. Levinas ha desarrollado una antropología interpersonal que destaca como verdad clara la primacía del otro, que 
La condición dialogal y comunitaria de la persona se pone de manifiesto en la palabra y en los sentimientos. El pensamiento inteligente madura con el desarrollo de la palabra; o dicho de otro modo, no puede existir un pensamiento áfono (habla interior o de reflexión inaudible) sin la vinculación con una lengua o palabra concreta. Ahora bien, la palabra se inserta en el ámbito de las relaciones intersubjetivas. Procede de un yo y va dirigida a un tú, procurando el desvelamiento del mundo y, sobre todo, la revelación de la persona. La libre y gratuita comunicación de su misterio inaccesible para el otro, al ser, en último término, inconceptualizable e inobjetivable ${ }^{37}$. Junto a ello recordemos que es especialmente a través del amor y el agradecimiento como adquirimos conciencia de nuestra condición y dignidad. Y ellos iluminan de modo relevante la dimensión intersubjetiva de la existencia ${ }^{38}$.

Por último, precisemos que individualidad y comunitariedad exigen un difícil equilibrio: «El hombre que rehúye su soledad (...) se vacía; el hombre que se entrega imprudentemente se pierde» ${ }^{39}$.

irrumpiendo en mi existencia (presencia inmediata o «epifanía del rostro») exige ser reconocido por el hecho de ser constitutivamente indigente. De este modo se alumbra un discurso ético que supera el nivel excesivamente privado e intimista de Buber. El yo se muestra bajo la mirada exigente del otro hombre, y la subjetividad debe ser acogida hospitalaria del otro. (Cfr. E. LEviNAs, Totalidad e infinito, Sígueme, Salamanca 1977; G. GonZÁlez R. ARnÁız. E. Levinas, Humanismo y ética, Cincel, Madrid 1987. Y para una panorámica de esta tradición personalista y dialogal: A. Domingo Moratalia, Un humanismo del siglo XX: El personalismo, Cincel, Madrid 1985). Con O. Ganzález de Cardedal podemos sentenciar que «La intersubjetividad es la piedra angular de toda ontología personalizadora». O. GonZÁleZ DE CARDEDAL, o.c., 197. (Cfr. también, 378). Digamos, por último, que la raíz bíblica del concepto de persona acabł descansando en «... la revelación trinitaria en que cada una de las personas son sí mismas sólo eñ la medida en que son relación, y por tanto tienen una condición absoluta que nace de la ordenación a los otros. Si el hombre es imagen de Dios, lo es hasta esos niveles, y no simplemente porque a diferencia del animal ande erguido, comprenda y construya. El hombre es imagen del únicơ Dios verdadero, y éste es unidad en comunidad, existencia única en relación de personas. Ricardo de San Víctor en la Edad Media será el primer autor que ponga en relación la idea de persona con el misterio trinitario y por ello habla de «existencia en relación» como lo constitutivo de lo personal». O. GONZÁLEZ DE CARDEDAL, o.c., 10, nota 11 .

37. Como diría E. Levinas, el otro no es calculable por ser abierto e imprevisible.

38. Cfr. el bello texto de Balduin SCHWARZ, Del agradecimiento, Universidad Complutense, Madrid 1985.

39. O. Gomez CAFFarena, o.c., 127. Decía Miguel Unamuno que el hombre de su tiempo estaba falto de soledad. Hay que abandonar la superficie de la conciencia para encontrarse consigo mismo en el diálogo interior. ¡A dentro! gritaba el rector de Salamanca. Hoy, como entonces, es necesario ese silencio cargado de tensiones, de vivencias e intuiciones, para alumbrar un proyecto que oriente la acción. Esta soledad es ascética mediación necesaria para la comunicación con los otros, y la toma de conciencia de nuestra propia mismidad. Cfr. M. DE UNAMUNo, Soledad, Espasa-Calpe, Madrid 1962, 31 ss; y el interesante ensayo de S. Álvarez Turienzo, El hombre y su soledad, Sígueme, Salamanca 183. 


\section{Temporalidad}

La existencia humana es temporalidad por ser realidad «distendida», «extática». La acción humana brota de esta estructura extática: la acción se inicia desde una situación en la que el hombre ya se encuentra (facticidad en la que el pasado está de algún modo presente como posibilidad) ${ }^{40}$, y se abre al futuro como proyecto vital ${ }^{41}$. A través de este último el hombre procura su autorrealización ${ }^{42}$. El hombre es un «ente sucesivo» ${ }^{43}$; el modo de ser íntimo del hombre implica, pues, el tiempo existencial. Tiempo que, como nos queda que ver, revela la limitación de la vida humana, al estar abocada necesariamente al paso último de la muerte.

\section{Historicidad}

Es una característica estructural del ser humano que se funda en su temporalidad: «En realidad, no es sino la integración de la temporalidad existencial con las características de personeidad, mundaneidad y comunitariedad» ${ }^{44}$. En la historicidad inciden, pues, la encarnación del hombre, la dimensión temporal de la existencia, su dimensión social e interpersonal, y la libertad. El sujeto humano es un ser histórico en la medida en que es una realidad personal distendida como facticidad y proyecto, centro de iniciativa abierto al mundo y en interacción con los otros; siendo, pues, copartícipe de una comunidad.

40. «Lo que somos hoy en nuestro presente es el conjunto de las posibilidades que poseemos por el hecho de lo que fuimos ayer. El pasado sobrevive bajo forma de estar posibilitando el presente, bajo forma de posibilidad. El pasado, pues, se conserva y se pierde». X. ZubIrI, Naturaleza, historia, Dios, o.c., 328. «... el pasado no es meramente el conjunto de lo que hemos sido y ya no somos, sino un "volverse-hacia» lo que se ha sido, asumiéndolo como propio». P. LAíN ENTRALGo, La espera y la esperanza, Rev. de Occidente, Madrid 1962, 293. Y más concretamente escribe comentando a Ortega: «... lo que he sido — mi pasado- lo soy en vista de mi futuro, bien como posibilidad negativa (para no ser lo que he sido), bien como recurso positivo (para, apoyándome en lo que hasta ahora he sido, ser desde ahora)». P. LAf́n ENTRALGo, o.c., 444. En fin, temporalidad significa imbricación de pasado, presente y futuro y no mera sucesión lineal: «El hacerse del vivir humano implica pues, que se es el pasado (y el futuro). La historia no es, por tanto, algo en lo que estamos, sino algo que somos». R. RodRíguez GARCía, o.c., 80.

41. «viendo mi porvenir en mi pasado me hago presente». P. LAín ENTRALGo, o.c., 294. Cfr. también E.M. UREÑA, Ética y modernidad, Universidad Pontifica, Salamanca 1984, 56.

42. El hombre no es de una vez por todas, sino que «La existencia es constante trascendencia, es decir, rebasamiento de lo que es; no se es más que por la libre realización de un más ser». Paul FouÉQUi, L'existentialisme. Que sais-je?, P.U.C. Paris, 1966, 42.

43. Cfr. P. Laín Entralgo, o.c., 508.

44. J. Gomez CafFarena, o.c., 138. Cfr. también J. Gevaert, o.c., 237-243. «Sólo la temporalidad propia, que es al par finita, hace posible lo que se dice un 'destino individual', es decir, una historicidad propia». M. HEIDEGGER, El ser y el tiempo, o.c., 416. 
La historicidad es el modo peculiar del existente humano, que da origen a la historia. Historia que viene a ser «el conjunto de acontecimientos (...) que tienen su raíz en la libertad personal y en la comunidad humana (personal y cultural) $\gg{ }^{45}$. En este sentido, la historicidad se plasma en la tarea de crear un mundo cada vez más humano, que se concreta en la búsqueda y la realización de los valores... Pero esta tarea se enfrenta a un reto tremendo: el del sufrimiento y la muerte. ¿Qué libertad y qué liberación puede existir si la muerte acaba haciendo desaparecer a cada una de las personas?» ${ }^{46}$.

\section{C) LA IRREPETIBILIDAD DEL SUJETO HUMANO}

Estas estructuras existenciales arrojan luz sobre la irrepetible individualidad humana, que, a su vez, otorga a la muerte del hombre una peculiaridad propia.

La individualidad animal es numérica, la propia del ejemplar de la especie. La unicidad de cada ejemplar está en el orden de la cantidad. Comparativamente hablando, la individualidad o unicidad del sujeto humano se basa en algo cualitativo, que le hace, en ese sentido, no connumerable, un individuo absoluto ${ }^{47}$. Es la propia de un ser libre, creador y responsable que hace su vida ${ }^{48}$. La vida del sujeto humano, propiamente hablando, no es conmutable, de ahí su dignidad como fin.

El hombre aunque, en algún sentido es connumerable por ser miembro de una especie (en alguna medida posee una «esencia universal»), en otro no ${ }^{49}$,

45. J. Gevaert, o.c., 233.

46. J. GEVAERT, o.c., 265.

47. Las personas «son los únicos casos de 'existencias independientes' (sustancias) que están individuadas en sí mismas exclusivamente. Justo porque no pueden ser individuadas por el espacio y el tiempo, ni por el número (...) - como los cuerpos materiales, por ejemplo-, sino que en cuanto puros centros de actos se hallan elevadas sobre el espacio y el tiempo (...), tienen que ser distintas y pueden serlo simplemente por obra de su pura esencia misma (su «ser» «persona»). Los cuerpos físicos y aun los cuerpos vivos pueden ser idénticos por su esencia y sin embargo distintos realmente por su distinta situación en el sistema del espacio y el tiempo. Las personas son realmente distintas en última instancia (...) por ser individuos absolutos». M. ScHELER, Esencia y formas de la simpatía, Losada, Buenos Aires 1957, 91-92. (Cfr. también, 104). Ya en el siglo XV Scoto afirmó que el «principium individuationis» no sólo descansaba en la materia cuantitativa, sino que era inherente a la «hacceidad» del sujeto humano. En este sentido y comparativamente hablando afirma I. Lepp: «En realidad, el animal no es más que especie, y sólo son los hombres los que, por vía de proyección antropomórfica, ven también en él al individuo». I. LEPP, La mort et ses mystères, Grasset, Paris 1966, 35.

48. También Sartre sostiene que el hombre al elegirse se hace finito y único. Cfr. J.P. SARTRE, El ser y la nada, Losada, Buenos Aires 1972, 667. Cfr. también V. JANKELEVITCH, o.c., 115 ss.

49. La unicidad humana «indica precisamente aquello que no pertenece ya a una naturaleza». J. Gevaert, o.c., 64. 
pues goza de una individualidad que descansa en su dignidad creadora y moral, y en su historicidad ${ }^{50}$. La raíz de la unicidad o irrepetibilidad histórica de la existencia humana está, pues, en la condición personal del sujeto humano. (Y ello más allá del problema que pueda plantear la moderna «ingeniería genética» con el posible alumbramiento de individuos «clónicos»). Como diría Zubiri la individualidad humana es ese modo de ser personal por el que esa persona es formalmente suya.

La irrepetibilidad se concreta también en la multitud de relaciones que constituyen al sujeto humano: cada persona, «a pesar de todo lo que le une a sus semejantes, es al mismo tiempo centro de perspectiva de su propio mundo $\mathrm{y}$ en este sentido tiene realmente su mundo que hace que todos los encuentros vitales se refieran a él de una manera particular y única». Lo irrepetible como cualidad afecta a «las relaciones que unen en el amar, ver y sentir con mi entorno» ${ }^{51}$.

$\mathrm{Y}$ es esta individualidad irrepetible, en la que vibra la dignidad de la persona, la que hace que nos resistamos a ver en la muerte del hombre un mero momento del ritmo de la vida biológica, un mero servicio a la especie. La desaparición del individuo humano «no puede ser asimilada a la de otro ser impersonal, que no tiene ese valor de lo insustituible» ${ }^{52}$. El problema de la muerte surge desde el momento en que «se reconoce al individuo humano el estatuto de la singularidad, el valor de lo único e irrepetible. Si el hombre es un ente anónimo, puro numeral de su especie, cuando un hombre muere nadie podrá decir que ha muerto alguien; (...) ahí no ha pasado nada. (...) La cosa cambia si muere una singularidad determinada (y, en cuanto tal, preciosa en sí misma); entonces la muerte es también 'el fin de un mundo determinado'» ${ }^{53}$.

50. «Es un rasgo esencial del existir humano (...) el hecho que el ser que tengo que construir se presenta siempre como propio, como mío, radicalmente individuado, y nunca como un caso o ejemplar de una esencia universal. La existencia es siempre un «quién» y no un «qué». R. RoDRíGUEZ GARCIA, o.c., 95.

51. H. THIELICKE, o.c., 29.

52. J.L. RuIZ DE LA PEÑA, El hombre y su muerte, o.c., 145.

53. J.L. RUIZ DE LA PEÑA, Muerte y humanismo marxista, Sígueme, Salamanca 1978, 10. Claro que ha aparecido en la cultura actual («postmodernidad») otra actitud que pretende rebajar «la importancia de nuestro ser individual». Una importancia que ya el psicoanálisis freudiano consideró una exageración narcisista: «Freud creyó ver cierta inflación infantil de la autoconciencia en muchos de sus pacientes cuando se representaban la muerte; infantil, por asemejarse esa autoestima a la de los niños que se creen «el sol de la casa»; inflacionaria, porque partiendo de ella, daban valores muy exagerados a las postulaciones de sentido, eternidad, justicia, etc. Esta estima inflacionaria de ellos mismos, aunque reprimida al inconsciente, les llevaba a esperar soluciones de trasvida para las limitaciones implacables de la existencia, e incluso a fantasear la ayuda de unos progenitores benévolos e inmortalizadores». A. TORNOS CUBILLO, El hombre creyente y de hoy, ante la muerte, Estudios eclesiásticos. Vol. 62, n. ${ }^{\circ}$ 240, Madrid, enero-marzo 1987, 50. 
Cuando descubrimos la dignidad de la persona nos resistimos a ver en la muerte de la misma la simple aplicación de una ley universal. La muerte de un ser personal es algo más «que la consecuencia singular de una propiedad general y abstracta llamada mortalidad» ${ }^{54}$. Como nos indica Jankélévitch, la experiencia de la muerte humana nos descubre una profundidad desconocida.

En resumen, la temporalidad existencial nos abre a la posibilidad necesaria del morir humano, y al descubrimiento de la muerte como un componente estructural ontológico de la persona. Ello, y el grado de individuación (dignidad) que dimana de ésta, reviste a la posibilidad del morir de un carácter peculiar y dramático. El gran reto, pues, que se le plantea a una reflexión filosófica sobre la muerte, como la que aquí intentamos, es ver si es posible alumbrar un sentido o significado de la muerte que, en alguna medida, la haga asumible en un proyecto de vida con los demás en el mundo. ¿Es la muerte reveladora de un límite absoluto para el hombre, o quizás reveladora de su vocación más fuerte a la vida?

Para hacer frente a este interrogante, en esta primera parte de nuestro trabajo, vamos a tener en cuenta algunas aportaciones de tres grandes filósofos: M. Scheler, M. Heidegger y J.P. Sartre.

\section{D) LA MUERTE COMO COMPONENTE ESTRUCTURAL DEL DEVENIR PERSONAL}

El hombre vive abierto y orientado hacia el futuro, y esta apertura y orientación le hace cobrar conciencia de la propia muerte. Este saber es, como indica $\mathbf{H}$. Thielicke, un signo específico de humanidad. Nuestro futuro se nos revela como un margen de tiempo para realizarnos, limitado por la muerte. En este sentido, entre otras cosas, estamos definidos por la muerte. Por tanto, nuestro conocimiento de la muerte se relaciona con la conciencia de nuestra temporalidad. Gracias a ella continuamente sabemos que el tiempo a nuestra disposición es limitado, además de orientado e irreversible ${ }^{55}$. No cabe volver a empezar de cero, sólo la conversión y reorientación asumiendo el pasado, que va quedando incorporado a nuestro ser.

El tiempo existencial del hombre presenta una dimensión interior, que no se puede entender con la concepción del tiempo lineal-físico. El hombre al vi-

Para esta actitud, que concibe la vida como una etapa transitoria del devenir del universo, querer sobrevivir le parece algo abusivo. Sin embargo, la concepción que aquí defendemos, y que se basa en la intuición de la dignidad personal, choca contra este planteamiento, con el que tendremos que dialogar críticamente.

54. V. JANKÉLÉVITCH, o.c., 12. Cfr. también, 13,22-23.

55. «en cada instante que consideremos jamás el ser viviente habrá estado más cerca de su muerte». V. JANKÉLÉVITCH, o.c., 105. 
vir, experimenta un pasado que crece a medida que pasan los años, y percibe un futuro que paralelamente decrece. Esto hace que, según M. Scheler, el hombre posea una clase de certeza sobre su muerte, que se funda, más allá del método empírico-inductivo y de la observación de su propia degradación biológica ${ }^{56}$, en una «experiencia interna». Sostiene M. Scheler que «Un hombre sabría, de algún modo, que la muerte lo ha de sorprender algún día, aunque fuera el único ser viviente de toda la tierra; lo sabría aun cuando nunca hubiera visto padecer a otros seres vivientes las transformaciones que producen la aparición del cadáver» ${ }^{57}$. La certeza de la muerte que aquí señala Scheler es la que se decanta en una aproximación gnoseológica, que destaca una intuición fenomenológica. Es, pues, un saber más profundo y radical que la convicción que tenemos de nuestra futura muerte, gracias al método empíricoinductivo. Confieso que esta certeza de la muerte que proclama Scheler exige un esfuerzo de disciplina filosófico-metodológico, para despojarnos y prescindir de la «convicción empírica» de la muerte, que probablemente es la primera que adquirimos desde el punto de vista psicológico.

Es una certeza que «está ya en cada una de las fases vitales, por pequeñas que sean, y en la estructura de su experiencia» ${ }^{58}$. La vida nos está presente como una «totalidad cerrada». Hay un fondo intuitivo en toda experiencia de la vida: ella se nos aparece «sobre el fondo de una unidad vital cerrada temporal-

56. El hombre puede llegar a una cierta certeza, aunque no rigurosamente apodíctica, de su propia muerte a partir de la observación de la muerte de sus congéneres. (Cfr. I. LEPP, o.c., 30,53; V. JANKÉLÉVITCH, o.c., 11). También las experiencias del propio envejecimiento y de la propia enfermedad pueden llevarle a la consideración de su futuro fin. Sería, como dice Scheler, como trazar y prolongar la dirección de la curva que marca este tipo de experiencias. Una certeza que también se ve corroborada por la investigación científica: «En calidad de biólogo puedo constatar el carácter finito de la posibilidad de vivir inherente a cada organismo; es decir, el hecho de que vivir significa luchar constantemente contra obstáculos y amenazas, y que cada organismo agota sus energías en esta lucha». P.L. LANDSBERG, Experiencia de la muerte, Cruz del Sur, Santiago de Chile-Madrid 1962, 33. (Cfr. también V. JANKÉLÉviTCH, o.c., 92,196). En la misma línea sostiene Laín que la vida orgánica es futurición «determinada» (según un ciclo inscrito en la constitución del organismo), y «determinante» (porque un estado concreto influye en la configuración de los que le siguen). (Cfr. P. Laín EnTRalgo, La espera y la esperanza, o.c., 480). No obstante la certeza que aquí defiende Scheler no tiene nada que ver con este tipo de experiencia externa, ni con la investigación científica.

57. M. SCHELER, Muerte y supervivencia, Goncourt, Buenos Aires 1979, 23.

58. M. SCHELER, o.c., 24. «... la muerte es un a priori para toda experiencia basada en la observación inductiva, que se tenga del cambiante contenido de cada proceso vital». M. SHELER, o.c., 26. Para hacernos ver esto, Scheler nos recuerda que la estructura de una fase puntual del proceso vital y de la conciencia que la acompaña, contiene un contenido con tres extensiones: «inmediato ser presente, pasado y futuro de algo». Estas extensiones se dan en tres tipos de actos: «inmediata percepción, inmediato recuerdo e inmediata espera». $Y$ «tanto el contenido del recuerdo inmediato como el de la inmediata espera están dados como activos en nuestra vivencia presente (no como idea previa)». M. SCHELER, o.c., 27. 
mente hacia adelante y atrás» ${ }^{59}$. Esta certeza, pues, no deriva de un dato sensible, sino que hay un «plus intuitivo» que sobrepasa la información sensorial. Precisamente cada una de las experiencias vitales se constituyen y adquieren un sentido emergiendo del fondo de esta intuición de la vida como totalidad cerrada, con un principio y un fin. (A ello aludiremos en el siguiente punto, al tratar de la «seriedad» de la vida).

La idea de la muerte es, pues, un elemento constitutivo de la conciencia humana, y la esencia de la muerte está ya contenida en la estructura de la vida. Defiende Scheler una intuición intelectual a priori de la muerte en la experiencia del proceso vital. La esencia de la vida incluye la necesidad de la muerte. La muerte es una nota coesencial o esencia coposible de la vida. Saber que vivimos es saber que moriremos ${ }^{60}$. De tal modo que, al final del proceso vital lo que está es sólo su imprevisible realización ${ }^{61}$.

Desde el punto de vista del tiempo objetivo, el contenido del ser, en cada momento, se divide en tres partes: ser pasado, ser presente y ser futuro. Y vivencialmente experimentamos que el volumen de este contenido se distribuye en una dirección determinada que no es sino «vivencia de la dirección de la muerte»: «El volumen del contenido en la extensión del pasado (...) y la experimentada inmediata repercusión de ese contenido de pasado, crecen y crecen,

59. M. SCHELER, o.c., 32.

60. El a priori para Scheler es una unidad significativa ideal (y su proposición correspondiente), dada en el contenido (fenómeno) de una intuición inmediata. Esta intuición es denominada por Scheler «de esencia», «fenomenológica» o también «experiencia fenomenológica». Una esencia se puede manifestar en un objeto, pero la verdad de la proposición que a ella se refiere no depende en particular de ese objeto, sino de dicha esencia. En ese sentido es verdad a priori. El contenido a priórico sólo se puede mostrar o hacerlo ver. (Cfr. M. ScHELER, Ética. T.I. Rev. de Occidente, Buenos Aires 1948, 83 ss y 91 ss). La esencia, pues, lo es con independencia de que yo la intuya o del objeto que la realice.

61. Cfr. M. Scheler, Muerte y supervivencia, o.c., 44. «De un lado tenemos la certeza absoluta de que hemos de morir alguna vez; de otro, nos invade la completa inseguridad de cuándo nos sorprenderá la muerte». D. von Hildebrand, o.c., 69. Como dice Jankélévitch, «El más previsto de los sucesos es paradójicamente el más imprevisible (...). De la afirmación de que todos los hombres son mortales no se deduce la fecha en que morirá una persona en particular». V. JANKELÉVITCH, o.c., 20-21. Y si la fecha de un hecho absolutamente cierto, como la muerte, es incierta, ello es debido, en último término, a una razón metafísica: «no se trata de una imprevisión accidental, sino de una indeterminación esencial (...) la muerte es imprevisible (...); el interesado no sabrá el secreto de su muerte propia más que en el último momento; el viviente no sabe la hora más que cuando la muerte está ahí, es decir, cuando cesa de vivir; porque él no vive jamás el presente de su muerte, y por tanto, hasta el instante supremo ignora la fecha. ¡Pues cuando la muerte haya tenido lugar será el viviente el que no será jamás! La determinación de esta certeza no es pues jamás más que póstuma (...) retrospectivamente, la muerte habrá sido un suceso determinado en todas sus coordenadas, pero sólo será presente para los supervivientes (...), ¡la hora de la muerte propia no es cierta más que en futuro anterior!». V. JANKELEVITCH, o.c., 135-136. (Cfr. también, 138 ss, 154 y 159). 
mientras simultáneamente el volumen del contenido en la extensión del futuro imendiato (...) y la anticipada actividad de éste contenido decrecen y decrecen. Pero el volumen del ser presente, situado entre los otros dos volúmenes, es, por así decirlo, cada vez más "comprimido» ${ }^{62}$. Esto es, el contenido cada vez mayor de lo vivido y su repercusión, disminuye la cantidad de lo que podremos experimentar. Esto se ve de modo palpable comparando las fases fundamentales de la vida: "para el niño el presente es una ancha y clara superficie del más variado ser. Pero esta superficie (...) se vuelve más y más estrecha, más y más comprimida entre repercusión del pasado y anticipación del futuro. (...) Con cada trozo de vida que es vivido (...) se estrecha sensiblemente el espacio de la vida que todavía se puede experimentar. El espacio del poder vivir pierde riqueza y plenitud, y la presión de la inmediata repercusión se vuelve mayor» ${ }^{63}$. La dirección, pues, de la vida la vemos como un consumo permanente de lo experimentable, que disminuye de volumen a medida que crece el de lo experimentado ${ }^{64}$. La estructura de todo momento vital experimentado encierra la vivencia de la dirección de la muerte: la extensión hacia el futuro llegará a ser nula ${ }^{65}$. En el darse de la vida se da la idea del límite; la vida son posibilidades limitadas. Para reforzar la tesis de M. Scheler nos viene bien caer en la cuenta de que todo proyecto biográfico que hacemos, lo concebimos como limitado. Y en fin, la certidumbre de nuestra propia muerte es tan absoluta que no puede fundarse, sin más, en el método empírico-inductivo ${ }^{66}$.

Claro que si la idea de la muerte es un elemento constitutivo de la conciencia humana, y la muerte está ya inscrita en la propia estructura de la vida del hombre, se debilita radicalmente el argumento de Epicuro. Argumento que, como nos recuerda P.L. Landsberg, vino a ser patrimonio común de la filosofía ecléctica de la antigüedad latina. Epicuro quiere librarnos del temor

62. M. SCHELER, Muerte y supervivencia, o.c., 28.

63. M. SCHELER, o.c., 28. Cfr. también V. JANKÉLÉviTCH, .o.c., 187, 189-190, 198.

64. En este sentido V. Jankélévitch llama al envejecimiento la «entropía general del tiempo vivido», y a la vejez «la enfermedad de la temporalidad». (Cfr. o.c., 191 y 192).

65. Cfr. Luis FArre, Antropología filosófica, Guadarrama, Madrid 1968, 411-412. H. Thielicke, o.c., 34,37. J.L. RUIZ DE LA PEÑA, El hombre y su muerte, o.c., 74,75.

66. Una ratificación de lo que pensamos respecto a la certeza empírica de la muerte se halla en este texto: «Cuando se reflexiona en ella críticamente se descubre sin dificultad que se limita a registrar la desaparición de hecho de todos los hombres que han existido hasta ahora. Esto no prueba que todos deban morir. (...) Sobre la base de la certeza experimental no será difícil razonarse y persuadirse que esta certeza está muy lejos de ser apodíctica». Y esto es lo que permite a algunos hombres inauténticos refugiarse en el mundo anónimo del «se», con la esperanza de escapar a la propia muerte. «Y si algunos hombres, menos fáciles al engaño, no experimentan la menor ilusión, la razón es que su certeza tiene fundamentos distintos de los del pensamiento cotidiano aun crítico". A. de WAELhENS, La filosofía de Martin Heidegger, Consejo Superior de Investigaciones Científicas, Madrid 1952, 143, nota 32. 
ante la muerte; temor que él cree infundado, pero que, no obstante, es corrientemente fuente de angustia e impedimento de la felicidad ${ }^{67}$. Nuestro filósofo intenta desdramatizar la muerte, partiendo de su filosofía sensista y hedonista. (Para él las sensaciones vienen a ser principio gnoseológico y ético). La reflexión filosófica nos puede liberar del miedo a la muerte, pues ella nos hace caer en la cuenta de que la muerte no es nada para nosotros. Mientras existimos no nos afecta, y cuando ella llega, nosotros dejamos de existir. Por tanto es un problema que, è verdad, no nos concierne en el tiempo, ya que vida y muerte se excluyen. Si la realidad se reduce al mundo de las sensaciones, la muerte pierde garra e importancia ${ }^{68}$.

Ahora bien, más allá de lo discutible que pueda ser el sensismo epistemológico y el hedonismo ético del epicureísmo, el argumento falla porque Epicuro concibe la muerte como algo que nos viene del exterior, mientras que como hemos visto, «la muerte se nos da por anticipado (...) en toda posible experiencia interior, de la que es elemento necesario y evidente» ${ }^{69}$. La facticidad de la muerte es sólo la confirmación de una certeza intuitiva, de una posibilidad negativa y necesaria, que acompaña a todos los momentos de la existencia del hombre. Certeza que nos presencializa la amenaza del no-ser. Y de ella no podemos desembarazarnos con un simple discurso retórico. Por ello, a los hombres les sigue conmocionando, no las posibles sensaciones dolorosas vinculadas a la experiencia del morir, sino la amenaza que ella conlleva respecto a nuestra persona ${ }^{70}$. Lo que nos angustia, como muy bien señaló Unamuno, es la negación de nuestro ser, es la nada ${ }^{71}$. Nada que por otro lado, nos es inac-

67. El objetivo principal de la filosofía de Epicuro, precediendo a L. Feuerbach, fue «disipar la angustia de espíritu que puede producir el desconocimiento de los dioses, el desconocimiento de la naturaleza, el desconocimiento del alma». B. FARRINGTON, La rebelión de Epicuro, Ed. Cultura popular, Barcelona 1968, 129. La filosofía de Epicuro no es sobre todo una meditación y preparación para la muerte, sino una filosofía de la vida, que intenta enseñar al hombre el camino de la sabiduría, que es el que conduce a la felicidad.

68. «Acostúmbrate a considerar -escribe Epicuro a Meneceo- que la muerte no es nada para nosotros, puesto que todo bien y todo mal están en la sensación y la muerte es pérdida de la sensación». «Así pues, el más estremecedor de los males, la muerte, no es nada para nosotros ya que mientras somos la muerte no está presente, y cuando la muerte está presente, entonces nosotros no somos. No existe, pues, ni para los vivos ni para los muertos, pues para aquellos todavía no es, y éstos ya no son». EpIcuro, Carta a Meneceo. Máximas capitales, Alhambra, Madrid 1985,47 y 48 . He aquí otro texto: «La muerte no es nada para nosotros. Porque lo aniquilado es insensible y lo insensible no es nada para nosotros». Epicuro, o.c., (Máxima N. ${ }^{\circ} 2$ ), 53. Cicerón divulgó el argumento epicúreo, y Lucrecio, Marco Antonio y Séneca, salvando matices, lo sostuvieron. Para una versión moderna del argumento: E.M. Croran, Ese maldito yo, Tusquets, Barcelona 1987,150 y 189.

69. J.L. RUIZ DE LA PEÑA, El hombre y su muerte, o.c., 76.

70. Cfr. P.L. LANDSBERG, o.c., 72.

71. Una amenaza mucho más traumática para Unamuno que la posibilidad de la condenación: «y he de confesar, en efecto, por dolorosa que la confesión sea, que nunca, en los días de la 
cesible, pues nuestro pensamiento «está dominado por la lógica de la vida» ${ }^{72}$, que se desarrolla con las categorías del ser. El argumento de Epicuro no es más que un juego de palabras, un sofisma, pues la amenaza de la aniquilación no puede ser detenida por el pensamiento ${ }^{73}$. Tiene razón von Hildebrand cuando afirma que «es falso creer que sólo el sufrimiento es un mal. La pérdida objetiva del ser es un mal terrible» ${ }^{74}$. E incluso desde la perspectiva hedonista, tendríamos que recordar a Epicuro las palabras de E. Bloch: «... el placer quiere, más bien, la eternidad» ${ }^{75}$.

\section{E) LA FINITUD Y LA SERIEDAD DE LA VIDA}

En la tarea personal e histórica, que es el realizarnos a nosotros mismos, la irreversibilidad de nuestra existencia temporal, y la muerte como el fin de nuestras posibilidades, le dan una «seriedad», una dignidad y un valor especiales a la vida y al elegir humanos ${ }^{76}$.

Los contenidos de una hipotética vida de continuidad indefinida, se tornarían para su protagonista, en relativamente indiferentes y ajenos, o al menos perderían garra y dramatismo. «En efecto - como dice Ferrater Mora-

fe ingenua de mi mocedad, me hicieron temblar las descripciones, por truculentas que fuesen, de las torturas del infierno, y sentí siempre ser la nada mucho más aterradora que él. El que sufre vive, y el que vive sufriendo ama y espera, aunque a la puerta de su mansión le pongan el ¡Dejad toda esperanza, «y es mejor vivir en dolor que no dejar de ser en paz». M. de UNAMUNo, Del sentimiento trágico de la vida, Ed. Plenitud, Madrid 1965, 39. Este horror a la nada lo mezclará con el que le suscita la soledad nihilizante y estéril (frente a la soledad positiva a la que ya hemos aludido). Cfr. M. de Unamuno, Diario, Alianza, Madrid 1970, 76. Ni siquiera el deseo de pervivir en la descendencia o en las obras del espíritu es un consuelo suficiente para Unamuno. También para E. Bloch es ésta «una inmortalidad metafórica» frente a la inmortalidad personal de la fe religiosa. Un consuelo además utópico y aristocrático, al alcance de unos pocos. Cfr. E. BLocH, El principio esperanza, T. III, Aguilar, Madrid 1980, 264-265. En una línea unamuniana se mueve el razonamiento de Jankélévitch. Cfr. o.c., 380.

72. H. THIELCKE, o.c., 19. Por esto Jankélévitch señala el carácter metalógico del instante de la muerte.

73. También Jankélévitch nos recuerda el poder retroactivo de esa cesación negativa (la muerte) para definir nuestra finitud. (Cfr. o.c., 270, 272-273). Y criticando el intento estoico de racionalizar y aniquilar el temor a la muerte escribe: «En efecto el consolador no tiene razón y razón a la vez: razón porque su silogismo es impecable; sin razón, porque el silogismo no nos dispensa de ningún modo del salto vertiginoso que hace falta dar, del dolor desgarrante que hace falta afrontar para aplicarse la ley a sí mismo». V. JANKÉLÉVITCH, o.c., 22.

74. D. von HILDEBRAND, o.c., 31 .

75. E. BLOCH, o.c., 205.

76. «La muerte es un aspecto esencial de la vida y del desarrollo. El concepto de tiempo, amor o trabajo, por ejemplo, serían muy diferentes en un universo inmortal». Ramona RuBio HERRERA, La muerte como proceso psicologico a través del ciclo vital, Pensamiento. Vol. $44 . \mathrm{n}^{\circ}$ 174. Abril-junio 1988, 249. Cfr. también V. JANKÉLÉvitch, o.c., 321. 
ningún acontecimiento podría afectar radicalmente a tal vida. Habría siempre tiempo para llevar a cabo cualquier proyecto, para desdecirse de cualquier intento, hasta para borrar con la acumulación de hechos en el tiempo lo que acabarían por ser las huellas levísimas, casi imperceptibles, del pasado. (...) La vida resultaría pues, (...) nula de sentido justamente porque podría tener todos los sentidos que quisiera.

(...) La muerte configura nuestro existir no porque sea lo único que importa, sino porque nada importa gran cosa sin ella» ${ }^{77}$. La finitud de nuestra existencia otorga a nuestros actos una importancia que eleva su dignidad: «Sin una limitación de nuestro tiempo de vida, nuestros actos cotidianos no ten-

77. J. Ferrater Mora, El ser y la muerte, o.c., 194. Cfr. también J.L. Ruiz de la PeÑa, El hombre y su muerte, o.c., 75 y 138. «¿Por qué hacer lo que se podría hacer igual de bien en mil años?». I. LEPP, o.c., 234. No obstante, este planteamiento debería ser matizado con la consideración de que la vida indefinida quedaría despojada de dramatismo, urgencias, etc., aunque no absolutamente de sentido, pues la moralidad y la historicidad, como notas del ser del hombre, implicarían el alumbramiento y la configuración de una personalidad continua e incesante. $\mathrm{Y}$ esto implicaría la posición de sentidos, aunque relativos y siempre superables.

Esta manera de ver la cuestión, basada en lo irreversible de nuestra temporalidad y lo irrevocable de nuestra conducta, nos lo recuerda acertadamente J.P. Sartre: «... aun cuando fuese inmortal, me sería igualmente vedado 'recoger mi apuesta': la irreversibilidad de la temporalidad me lo prohíbe, y esa irreversibilidad sino es sino el carácter propio de una libertad que se temporaliza. Ciertamente, si soy inmortal y he debido descartar el posible B para realizar el posible A, volverá a presentárseme la ocasión de realizar el posible descartado. Pero por el sólo hecho de que esta ocasión se presentará después de la ocasión rehusada, no será la misma y, entonces me habré hecho finito para la eternidad al descartar irremediablemente la primera ocasión». J.P. SARTRE, El ser y la nada, o.c., 667.

Si lo irreversible se predica del «haber sido», lo irrevocable se predica del «haber hecho». A lo irreversible del devenir se añade lo irrevocable del hacer: «... con nuestras propias manos (...) fabricamos lo irreparable que volverá lo irreversible todavía más irremediable». (V. JANKÉLÉVITCH, o.c., 331). Y si lo irreversible tiene por origen el hecho puro de la sucesión, lo irreparable nace de nuestra libertad: «El hecho de haber tenido lugar es literalmente inexterminable». (V. JANKÉLÉVITCH, o.c., 334); «... el hecho de haber hecho, ese, no puede ser desecho» (V. JANKÉLÉVITCH, o.c., 33. También, 336-338). Y esto da seriedad moral a nuestra historicidad: «Lo irreversible, y más todavía lo irrevocable son para el hombre una amarga y dura invitación a la seriedad». (V. JANKÉLÉvITCH, o.c., 368). Digamos, por último, que «Lo irreversible expresa que cada instante es único, es decir a la vez primero y último». (V. JANKÉLÉVITCH, o.c., 300). Es esta paradoja lo que Jankélévitch denomina la «primultimidad» de cada instante.

Otra cuestión será la «calidad» de esa hipotética vida sin fin. Recordemos al respecto al "Conde Fosca», personaje de Simone de Beauvoir, que tras haber conseguido, con un brebaje, la inmortalidad, acaba deseando la muerte de todos los humildes mortales, hastiado de tanta soledad y mediocridad. (Cfr. S. de BEAuvoIR, Todos los hombres son mortales, Edhasa. Barcelona s.f.). A esta hipotética, monótona y mediocre inmortalidad la denomina Hildebrand «infierno». (Cfr. D. von HILDEBRAND, o.c., 14). Y frente a ella escribe A. Basave: «La vida terrenal aunque no concluyera nunca, no podrá satisfacer ese anhelo de plenitud substancial que coexiste orgánicamente -en el estadio mundano - con el desamparo ontológico: La única posibilidad de satisfacer ese afán de plenitud subsistencial nos lo brinda la muerte con su allendidad». (A. BASAVE, o.c., 243-244). Sin la muerte, sin la posibilidad de la muerte, se cuestionaría lo trágico del suicidio, y sobre todo el heroísmo y el valor de determinados actos. 
drían esa (...) vigencia febril, esa calidad permanente de elección, y esa fundamental dignidad. Nuestra propia finitud es una 'oportunidad única' que nos es ofrecida por la vida, o, si se prefiere, por la muerte» ${ }^{78}$. Como dice A. Basave, «Justamente porque voy a morir no me pueden ser indiferentes las diversas posibilidades que se me ofrecen en mi vida» ${ }^{79}$. Desde esta perspectiva, la muerte se ve y se puede vivir como consumación del «status viatoris» ${ }^{80}$. Se ve como el paso con el que el hombre se define irremediablemente, se da, se perfila el destino total de su existencia. La muerte se convierte así en un acto de suprema interioridad, que brota del núcleo más personal del sujeto que lo lleva a cabo. Y ello porque en la muerte el hombre dispone sobre la totalidad de la existencia con una radicalidad y eficacia como jamás le fue concedido en etapas anteriores de su vida. La muerte es el acto supremo en el cual el hombre realiza de forma total su existencia, usando de su libertad ${ }^{81}$. Desde esta óptica diríamos que es la acción humana de mayor densidad y trascendencia; lo que demuestra la necesidad de asumir la propia muerte como un compromiso ético. Cuando se afirma en primera persona «me muero», se alude a una experiencia personal en la que el sujeto pondrá en juego el secreto de la propia existencia. Mi muerte «es un acontecimiento personal que me pertenece sin confusión posible» ${ }^{82}$. La muerte es una oportunidad única y límite ${ }^{83}$ para la con-

78. Jean ZIEGLER, Los vivos y la muerte, F.C.E. México 1976, 307. Cfr. tambièn V. JANKÉLÉVITCH, o.c., 94-95, e I. LEPP, o.c., 233-234.

79. A. BASAVE, o.c., 64.

80. Con esta expresión «... se designa el estado dinámico de un ser que todavía no es, que aún está por consumar y perfeccionar, pero que está estructurado en una exigencia de consumación, de perfección y total verificación». J. PIEPER, Muerte e inmortalidad, Herder, Barcelona 1970, 134.

81. «Entonces -y sólo entonces - se opera el acto decisivo y supremo de «autodisposición». Cada uno se escoge a sí mismo en el acto de la muerte de modo singular, inimitable, inopinado... Y no hay ulteriores opciones. Seremos lo que queremos ser». A. BASAVE, o.c., 58 y 59. (Cfr. también 11, 14 y 153); y (J. PIEPER, o.c., $135 \mathrm{ss}$ ). En este sentido también von Hildebrand destaca el carácter solemne de la muerte: «... su absoluta unicidad no se puede comparar con ninguna otra cosa en la vida». D. von HiLDEBRAND, o.c., 123.

82. H. THIELCKE, o.c., 261. Muy heideggerianamente escribe Jankélévitch: «... no se puede morir en lugar de otro en general; esto es algo que tiene que hacer uno mismo, y en lo que nadie puede reemplazar a nadie». V. JANKÉLÉVITCH, o.c., 164. En último extremo «La muerte es el único suceso que no se puede convivir» A. BASAVE, o.c., 90. «Pasar por la muerte es pasar por la soledad absoluta...» N. BERdIAEFF, Cinco meditaciones sobre la existencia, Casa unida de Publicaciones, México 1948, 115.

83. El nacimiento es un acontecimiento «absolutamente virgen de todo pasado». No conoce sino la llamada del futuro. En cambio la muerte como «última vez» está despojada de futuro y cargada con el peso del pasado. Por eso Jankélévitch llama al nacimiento la «dernière toutepremière fois», y a la muerte la «première toute-dernière», (o.c., 301 y 317). La «primultimidad» de la muerte es absoluta, no relativa: «Morir es (...) una cosa sin precedente y sin día siguiente» (o.c., 313). Además la muerte presenta una irrevocabilidad superlativa, pues si la serie intravital, 
versión y la autenticidad. De ello da testimonio el deseo del moribundo de poner en orden las cosas. Ante la imposibilidad de la acción exterior, éste último se vuelve hacia sí mismo, y ve surgir su pasado. «Medita sobre sus actos: los públicos y los secretos. Ya no es hora de trampas» ${ }^{84}$. Es decisivo el testimonio de los que han estado «al borde la muerte». En esos momentos «se produce un auténtico desencadenamiento de recuerdos, como si toda la vida desfilara ante el sujeto en una rapidísima sucesión cinematográfica». "Una de las actitudes ante la muerte podría ser, pues, la de la recapitulación del vivir» ${ }^{85}$. Y ello porque, como muy bien indica Thielicke, «Sólo cuando aparece el todo, se puede apreciar también el lugar y significación de cada acontecimiento particular en el interior del todo" ${ }^{86}$.

El conocimiento de nuestra futura muerte nos anticipa toda la existencia como proyecto y posibilidad de éxito o fracaso.

Si tenemos en cuenta todo lo dicho, se comprende que Heidegger considere a la muerte como la posibilidad más personal.

\section{F) LA MUERTE COMO POSIBILIDAD RADICAL}

Toda la reflexión filosófica de Heidegger sobre la muerte es una llamada a la necesidad de interiorizar la propia muerte ${ }^{87}$.

a pesar de su irrevocabilidad, en álguna medida, puede ser asumida y superada en un proyecto de conversión, la muerte, en este sentido, es inasumible... No hay otra situación posterior para asumirla (con aprobación, arrepentimiento, reparación, corrección, etc.).

No son pocos los pensadores que han destacado a la filosofía como preparación-aprendizaje de la muerte (Platón, Séneca, Montaigne, etc.). No obstante, Jankélévitch señala que no cabe un aprendizaje de la muerte. Se puede aprender conductas que vienen a ser procesos constituidos por momentos componenciales, distinguibles analíticamente, y en donde cabe la repetición y el tanteo. En este sentido no cabe una propedéutica de la muerte (V. JANKÉLEVITCH, o.c., 314), que se caracteriza por su primultimidad absoluta y su «inasibilidad». No obstante, una concepción de la realidad, de la vida y de la muerte, y una vida coherente con la misma, nos pueden ayudar a adoptar una actitud auténtica ante la muerte, que nos impida que ésta nos coja por sorpresa y «sin saber qué hacer». Y esto es algo que acaba reconociendo el propio Jankélévitch: «Sería pues exagerado pretender que la manera de morir no tenga ninguna relación con la meditación de la mortalidad». (o.c., 278). G. Lukács, inspirado en las narraciones de L. Tolstoi, nos recuerda que suele haber una correlación entre el modo de vivir y la manera de morir: «la vida vivida con sentido se cierra con una muerte vivida con autodominio; la vida vivida sin sentido se termina en una lucha sin esperanza y llena de torturas con el final sin sentido». G. LuKACs, De cuestiones liminares de lo estético, En VARIOS, Sobre la religión II. Sígueme, Salamanca 1975, 584. Es difícil enfrentarse con autenticidad y sentido a la muerte si estas notas no nos han acompañado a lo largo de la vida. Cfr. I. Delsle-LAPIERRE, Vivir el morir, Paulinas, Madrid 1986, 21, 22, 27. Cfr. también I. LePP, o.c., 211, 212, 217, 218, 225.

84. A. Basave, o.c., 66. Cfr. también von Hildebrand, o.c., 56.

85. J. Ferrater Mora, El ser y la muerte, o.c., 216 y 217.

86. H. Thielicke, o.c., 71. Cfr. también V. JANKÉlévitCH, o.c., 123.

87. La siguiente exposición está, en parte, inspirada en J.L. RuIZ dE LA PEÑA, El hombre y su muerte, o.c., 79 ss. 
Heidegger se enfrentó al problema ontológico abordando el análisis óntico del existente humano, ya que el hombre es el único ente que es capaz de preguntarse por el ser ${ }^{88}$. Y en esta tarea se vio abocado a reflexionar sobre la muerte.

El «ser-ahí» (Dasein) ${ }^{89}$ tiene que conquistar su autenticidad asumiendo sus propias posibilidades, en cuanto ser en el mundo. En esta tarea el «serahí» se relaciona con los otros existentes, y trata o «cuida» de ellos. Es el «cuidado» una estructura unitaria del «ser-ahí», que presenta unos modos o existenciales referidos entre sí: el «encontrarse», el «comprender» y la «caída» ${ }^{90}$.

Con el término «encontrarse», Heidegger expresa un elemento estructural de la existencia: la condición afectiva de nuestro ser en el mundo. En el mundo somos, en las distintas situaciones, con diversos estados de ánimo. El sentimiento tiene para nuestro filósofo, un significado ontológico, un carácter informativo, por el que nos dice «cómo nos va», y, en definitiva, nos abre nuestro propio ser como facticidad, como puro hecho de existir, como arrojamiento. El «estar arrojado» significa que previamente a toda reflexión, nos encontramos, sin elegirlo, en una situación determinada, teniendo que realizarnos. Por tanto en el «encontrarse», el «ser-ahí» se revela a sí mismo como facticidad, como existencia arrojada, como «estado de yecto», de un ser ya en el mundo. Estado que, al no haber sido elegido por él, le hace sentirse abandonado ${ }^{91}$.

88. Para Heidegger, y por influencia de Aristóteles, el problema del significado del ser (unidad o diversidad de sentidos), es el problema fundamental de la filosofía. Al problema ontológico dedicó 60 años de vida intelectual. Y en destacar la importancia de dicho problema, creo que acertó, pues el ser se nos aparece como la máxima interpretación de la realidad. La pregunta por el ser se revela como «la tarea crítica por excelencia, porque «ser» es el concepto siempre presente en todo intercambio hombre-mundo, el supuesto por antonomasia». R. RodRíguez GARCía, o.c., 53. La existencia humana se le revela como un modo de plantear la pregunta por el ser; dicha pregunta está inscrita en la naturaleza del hombre. En su obra fundamental «El ser y el Tiempo», intenta el «replanteamiento de la pregunta por el sentido del ser a partir del análisis de su comprensión en la facticidad de la existencia humana». R. RodRíguez GARCía, o.c., 53. El hombre posee una comprensión pre-conceptual (pre-comprensión) del ser. Cuando usamos el término lo entendemos aunque sea de un modo impreciso. Por ello, para Heidegger, la existencia humana es el «lugar» donde podemos alcanzar a determinar el sentido del ser. El análisis de dicha existencia es, pues, la base $\mathrm{u}$ horizonte trascendental desde el que se debe acceder a la elaboración del concepto de ser. Al existente humano le es constitutivo una relación a ser (comprensión der ser), porque como ya dijimos en la Introducción, el ser humano tiene que habérselas consigo mismo, tiene que ocuparse de ser. Un «tener que ser» que implica una comprensión del mundo y de las cosas.

89. Dasein es la existencia humana como comprensión o lugar del ser; el ámbito en el que hay o aparece ser.

90. El cuidado integra en una unidad los existenciales del ser en el mundo (encontrarse, comprender, habla...). Más tarde, Heidegger insistirá en el Dasein como el que cuida la verdad del ser, como «el pastor del ser». Cfr. M. HEIDEgGER, Carta sobre el humanismo, o.c., 27, 40, 41.

91. Cfr. M. HeIdegGer, El ser y el tiempo, o.c., 152 ss; R. Rodríguez GarCía, o.c., 104 ss. 
En segundo lugar, la existencia se autotrasciende, partiendo y sabiendo de este «estado de yecto, anticipándose, existiendo fuera de sí, como proyecto ${ }^{92}$. El comprender es, pues, «proyecto» o «existencia». El hombre intenta comprender las posibilidades que le ofrece el pasado y proyectarlas en el futuro. El «comprender» alude al poder ser que «hace que el mundo sea un ámbito de posibilidades» ${ }^{93}$.

Como muy bien indica R. Rodríguez García, el «comprender» «no es primariamente un acto de conocimiento o intelección. (...) es una estructura o forma de ser del propio existir, un modo de ser en el mundo que es previo a la disyunción ser-conocer y que, por tanto, es en cierto sentido, ambas cosas a la vez» ${ }^{94}$.

Pero el ser-ahí está en el mundo con los demás existentes, y ello implica la posibilidad de sumergirse en el anonimato del «se» (el impersonal gregario). Ello constituye la «caída». Es el modo trascendental del cuidado por el que el Dasein se entrega a la vulgaridad de la realidad cotidiana ${ }^{95}$. De este modo de ser impropio e inauténtico sólo puede ayudar a salir, o impedir caer en él, un modo del «encontrarse»: la «angustia». Con la angustia, el Dasein se descubre como ser desvalido al descubrir un mundo fútil, inane, que no puede albergarle ${ }^{96}$.

92. «Proyecto es la forma de ser de un ente que sólo existe vertiéndose hacia sus posibilidades». R. RodRiguez García, o.c., 109-110.

93. R. Rodriguez Garcia, o.c., 213. Cfr. M. Heidegger, o.c., 160 ss, 166 ss, 212 ss. En este sentido, la constitución originaria del ser-ahí se destaca como «un pre-ser-se en el ser ya-en un mundo». M. HeIDEGGER, o.c., 212. O «El ser del ser ahí quiere decir: pre-ser-se-ya-^n (el mundo) como ser cabe (los entes que hacen frente dentro del mundo)», o.c., 213. Esta oscura definición alude al «cuidado». "La expresión pre-ser-se (...) responde a la estructura del poder ser como proyecto: al proyectarme eligiendo mis posibilidades, voy como por delante de mí mismo, anticipo constantemente lo que voy a ser. «Ser ya en» no es otra cosa que la facticidad, el arrojamiento en el mundo (...). Mundo es, así, el ámbito de posibilidades y término de arrojamiento». R. RodRiGUEZ GARCÍA, o.c., 115.

94. En este sentido, es la condición ontológica de la posibilidad de todo comprender en sentido cognoscitivo. Esta proyección de la existencia no es concebida primariamente «como una actividad subjetiva que pone o constituye sus objetos, sino como la apertura de un campo gracias al cual las cosas pueden aparecer siendo esto o lo otro. La anticipación que el proyecto conlleva tiene justamente ese sentido: abrir un ámbito previo dentro del cual la acción y el conocimiento pueden ejercerse. El mundo, como término del proyecto originario, es ese espacio de sentido, supuesto en toda proyección concreta de posibilidades (...) el horizonte en el cual no sólo las cosas, sino el propio yo pueden ser». Lo que hay que comprender es «un estar a priori abierto a un ámbito de manifestabilidad, el mundo». R. Rodriguez GARCía, o.c., 133 y 134.

95. Cfr. M. HeIDEgGer, o.c, $185 \mathrm{ss,} 195 \mathrm{ss}$. Là caída viene a ser una tendencia estructural del Dasein a interpretarse a partir de lo inmediato, de las cosas, no asumiendo propiamente su ser. Es existencia inauténtica, pérdida de sí mismo. En este sentido tiene un alcance ontológico. Cfr. M. Heidegger, Carta sobre el humanismo, o.c., 29.

96. Cfr. M. HeIdegGer, El ser y el tiempo, o.c., 204 ss, y R. Rodríguez García, o.c., 116. $\mathrm{La}$ angustia brota también por tener que existir eligiendo. 
El ser-ahí, pues, se nos revela como un ser que se proyecta hacia el futuro en perpetuo inacabamiento, y ello manteniéndose entre dos posibilidades: la autenticidad o la inautenticidad. Para lograr una visión del ser-ahí en su totalidad, y captarle en la autenticidad de su ser, es necesario tener en cuenta la muerte. El ser-ahí sólo nos podrá ser accesible en la totalidad de su ser íntegro, cuando llegue a su extrema posibilidad: la muerte ${ }^{97}$. Claro que el problema está en que la llegada de ésta nos priva del objeto de nuestro análisis: el Dasein mismo ${ }^{98}$. Junto a ello, también debemos de reconocer la inexperimentabilidad de la propia muerte ${ }^{99}$. Y aunque podamos abrirnos a la muerte de los otros, esta experiencia, según Heidegger, no nos es suficiente, pues por su ipseidad, el ser-ahí no puede transferir su muerte a otro ${ }^{100}$.

No obstante el planteamiento hasta aquí seguido adolece de una cierta suficiencia, ya que en él subyace una concepción de la muerte como un «suceso puntual», que solamente sobrevendrá al hombre desde fuera. Frente a ello debemos de recordar, dirá Heidegger, que la muerte, en verdad, es un elemento ontológico del ser-ahí, esto es, una posibilidad constantemente presente. Profundizando en la línea de M. Scheler, la muerte es para Heidegger un modo de ser que el ser-ahí tiene que asumir desde el momento en que es: «El finar mentado con la muerte no significa un «haber llegado al fin» el «ser ahí», sino un ser relativamente al fin de este ente. La muerte es un modo de ser que el «serahí» toma sobre sí tan pronto como es. «Tan pronto como un hombre entra en la vida, es ya bastante viejo para morir» ${ }^{101}$. La muerte como elemento on-

97. «La pregunta acerca de la totalidad del «ser ahí» (...), implica hacer un análisis positivo de fenómenos de la existencia omitidos hasta aquí. En el centro de estas consideraciones está la caracterización ontológica del «ser relativamente al fin» en la forma del «ser ahí» y la obtención de un concepto existenciario de la muerte. M. HeIDEgGER, o.c., 259.

98. «Alcanzar la totalidad del 'ser ahí' en la muerte es al par la pérdida del ser del 'ahí'». M. HEIDEGGER, o.c., 260.

99. «El tránsito al 'ya no ser ahí' saca al 'ser ahí' justamente de la posibilidad de experimentar este tránsito y de comprenderlo como experimentado». M. HEIDEGGER, o.c., 260.

100. «La muerte se desemboza sin duda como una pérdida, pero más bien como una pérdida que experimentan los supervivientes. En el padecer la pérdida no se hace accesible la pérdida misma del ser que 'padece' el que muere. No experimentamos en su genuino sentido el morir de los otros, sino que a lo sumo nos limitamos a 'asistir' a él». M. HeIDEGGER, o.c., 261. Comentando este punto resume un estudioso de nuestro autor: «... nada sabemos de lo que es la muerte para el moribundo. No asistimos a la muerte, sólo podemos asistir al agonizante. Nos es posible, a lo más, observar exteriormente el paso de una existencia del tipo Dasein a una existencia de un tipo análogo al de las res (...). No puedo, por tanto, experimentar la muerte de otro, ni en cuanto morir, ni en cuanto tránsito del Dasein a la reificación ni aun siquiera en cuanto desaparición de la persona que muere. Porque el muerto no ha desaparecido verdaderamente para sus prójimos, la existencia en común con él no se ha roto. Todas las ceremonias fúnebres con que se le honra son para nosotros un objeto de preocupación y un modo de solicitud, por cuya virtud perseveramos unidos a él». A. DE WAELHENS, o.c., 142-143.

101. M. HeIDEGGER, o.c., 268. 
tológico hace que el ser-ahí sea un ser para el fin, para la muerte. Y si la muerte es un modo de ser del Dasein, podrá ser considerada en las tres dimensiones de la existencialidad, a las que ya hemos aludido ${ }^{102}$.

Así, desde el «encontrarse» — como asunción del ser dado- la muerte se le revela al Dasein como una situación que le viene dada desde el nacimiento. Desde su condición de «ser-yecto», la muerte se le aparece como su posibilidad inherente, irreferible e intranscendible ${ }^{103}$. Desde el «comprender» o «proyecto», la muerte aparece como la posibilidad en la que «le va al ser ahí» su «ser en el mundo» absolutamente. Su muerte es la posibilidad del «ya no poder ser ahí» ${ }^{104}$. Posibilidad ante la que el Dasein se angustia ${ }^{105}$ : «En la angustia ante la muerte resulta puesto el «ser-ahí» ante sí mismo en cuanto entregado a la responsabilidad de la posibilidad irrebasable» ${ }^{106}$.

Por último, en la «caída» como tercer modo del cuidado, el ser-ahí camufla la condición de permanente posibilidad de la muerte, distrayéndose en el mundo del «se». Es la muerte encubierta en el anonimato, un «ser relativamente a la muerte» impropio ${ }^{107}$. En fin, más allá del estricto plano ontológico, y dándole un carácter ético a la caída, diremos que implica una huida de uno mismo, que no es sino un estilo de vida en el que no puede brotar el autoconocimiento profundo y personal del ser relativamente a la muerte. El distraimiento es la represión de lo que angustia, y el objeto de la distracción es uno mismo como ser inquieto y angustiado. La huida centrífuga despersonaliza, aliena y malogra la llamada que encierra el sí mismo a la problematicidad, a asumir las cuestiones existenciales de una manera responsable y creativa, que densifica y realiza al yo en un proyecto personal. La muerte es la ocasión para el encuentro consigo mismo, y se teme porque puede ser que nos encontremos con un desconocido: ¡nuestro propio yo!

Pero ¿cómo salir de esta inautenticidad? ¿Cuáles son las condiciones existenciales de un comportamiento auténtico ante la muerte? Para Heidegger

102. «Existencia, facticidad, caída caracterizan el «ser relativamente a la muerte» y son por tanto ingredientes constitutivos del concepto existenciario de la muerte». M. HEIDEGGER, o.c., 275.

103. «... desde el momento en que el 'ser ahí' existe, es también ya yecto en esta posibilidad (...). El 'ser relativamente al fin' (...) es esencialmente inherente al 'estado de yecto' del 'ser ahí' que se desemboza de tal o cual manera en el encontrarse». M. HeIDEGGER, o.c., 274.

104. M. HeIDEgGer, o.c., 273. Cfr. también o.c., 274.

105. Cfr. M. HeIDEGGER, o.c., 274.

106. M. HEIDEGGER, o.c., 277.

107. Cfr. M. HeIDEGGER, o.c., 275-278 «Uno dice: la muerte llega ciertamente, pero por ahora aún no. Con este 'pero...' le quita el uno a la muerte la certidumbre. (...) Así encubre el uno lo peculiar de la certidumbre de la muerte, el ser posible a cada instante. A la certidumbre de la muerte va unida la indeterminación de su cuando». M. HeIDEGGER, o.c., 281-282. Cfr. también H. THIELICKE, o.c., 44-45. 
«Un «ser relativamente a la muerte» propio no puede esquivarse ante la posibilidad más peculiar, irreferente, encubriéndola en esta fuga e interpretándola torcidamente o al alcance de la «comprensividad» del uno» ${ }^{108}$. Un «ser relativamente a la muerte» propio deberá de implicar la comprensión de la muerte como su posibilidad más característica, radical y extrema, «La muerte es la más peculiar posibilidad del «ser-ahí» ${ }^{109}$. No es una posibilidad «a la mano», sino del «ser-ahí». Hay que comprenderla sin debilitar dicha posibilidad, y por tanto no sólo pensarla sino esperarla ${ }^{110}$. Este esperar implica introducir «bajo la forma de la espera lo posible en lo real» ${ }^{111}$. Y así la muerte se desvelará para él en cuanto posibilidad «como la de la imposibilidad de la existencia en general» ${ }^{112}$. El «ser ahí» proyectándose sobre su poder ser más peculiar, la muerte, significa comprenderse a sí mismo, esto es existir propiamente, auténticamente ${ }^{113}$. Y la muerte «reivindica a éste en lo que tiene de singular» ${ }^{114}$; lo singulariza en sí mismo, en la medida en que es irreferente. El talante auténtico será el que implica un reconocimiento de la muerte como la posibilidad de su ser total. Esto es lo que significa «correr al encuentro de la muerte». La muerte es la posibilidad que reduce a la nada el resto de las posibilidades, y por tanto la posibilidad que nos hace patente la totalidad de la existencia. La angustia es un modo fundamental de nuestro existir que nos revela nuestra condición de entes arrojados a la existencia y abocados a la muerte. Existir auténticamente es, pues, existir desde la permanente posibilidad del morir. «El 'ser relativamente a la muerte' es en esencia angustia» ${ }^{115}$. De esta posibilidad radical, que es la muerte, están transidas las demás posibilidades, constituyéndolas en su modo de ser; esto hace que sean posibilidades finitas y como tales deben ser asumidas ${ }^{116}$. Mediante la aceptación del ser para la

108. M. HEIDEGGER, o.c., 284.

109. M. HeIDEGGER, o.c., 287.

110. Cfr. M. HEIDEGGER, o.c., 285.

111. M. HEIDEGGER, o.c., 286.

112. M. Heidegger, o.c., 286. «La muerte como posibilidad no da al 'ser ahí nada 'que realizar', ni nada que como real pudiera ser él mismo. La muerte es la posibilidad de la imposibilidad de todo conducirse relativamente a, de todo existir». M. HEIDEGGER, o.c., 286. Cfr. también 289.

113. «El ser ahí sólo puede ser propiamente él mismo cuando se pone en posibilidad de ello desde sí mismo» M. HEIDEGGER, o.c., 287.

114. M. HEIDEGGER, o.c., 287.

115. M. HEIDEGGER, o.c., 290.

116. Cfr. M. HeIDEGGER, o.c., 288. Como comenta De Waelhens, todas las potencialidades constitutivas del Dasein «están dominadas y como en suspenso por una posibilidad suprema y en alguna manera 'fuera de serie', que está incluida en el Dasein y dueña de él en todo momento». A. de WAELHENS, o.c., 151. «Mirando a su propia muerte en su plenitud de significado (...), el Dasein auténtico acepta su más extrema posibilidad y la reconoce como pura nada. A su luz se 
muerte, el ser-ahí, en su presente, recapitula el pasado y el proyecto hacia el futuro. Aceptamos el ser para la muerte al que hemos sido arrojados, y la anticipación de la muerte como proyecto. De este modo la muerte se nos aparece como fundamento de la historicidad humana.

Para Heidegger, pues, como para Scheler ${ }^{117}$, la muerte es un elemento estructural, que como posibilidad siempre presente aunque no predecible, debe ser asumida por el Dasein en la angustia. El asumir esta posibilidad radical, que determina a todas las demás y que amenaza con el no ser ya, es condición del «comprender»o «existir» auténtico. Este «estar a la muerte» (Sein zum Tode) revela al ser-ahí como finito. Existencia auténtica, es para Heidegger, existir desde sí mismo aceptando libremente la posibilidad del morir (indigencia) como la máxima posibilidad, y la más propia y personal del individuo ${ }^{118}$. Confirma al hombre en su singularidad y le define por su libertad para morir.

$\mathrm{El}$ análisis heideggeriano sobre la muerte, aun reconociendo su rigor, nos suscita una inquietud. La muerte comienza siendo señalada como una estructura ontológica de la existencia y acaba siendo cantada como la posibilidad límite y extraordinaria. ¿Esto no termina volviéndola inocua? ${ }^{119}$. ¿Es que se puede erigir a la muerte en sentido de la vida humana? ¿Más allá de la conquista de la mismidad, la muerte no es, a la postre, la expropiación definitiva? ${ }^{120}$. Esta última es precisamente la tesis de J.P. Sartre.

\section{G) LA MUERTE COMO LA ANIQUILADORA DE TODA SIGNIFICACIÓN}

Como se sabe, Sartre desarrolla en su obra capital, «El Ser y la Nada», na ontología fenomenológica. Para nuestro autor, el fenómeno es un «relativo-absoluto» ${ }^{121}$. El fenómeno supone alguien a quien aparece (relativo), y a

comprende a sí mismo como nada». A. de WAELHENS, o.c., 154. Sobre la posibilidad de un más allá de la muerte, Heidegger no se pronuncia en principio, ya que su análisis fenomenológico gira en torno al ser en el mundo.

117. He aquí algunos puntos de coincidencia de estos autores señalados acertadamente por J.L. Ruiz de la Peña: «a) La muerte pertenece a la vida; puede y debe ser vivida anticipadamente en la existencia; b) su certidumbre no brota de la empiría; c) muy al contrario, ese saber experiencial sofoca lo que la muerte tiene de estímulo y llamada a una existenia auténtica, tentando al hombre para que se pierda en el anonimato del 'se muere', (...); e) la muerte debe ser afrontada con plena libertad, activa y no pasivamente; f) de este modo, será el cumplimiento del sentido auténtico de la existencia». J.L. RUIZ DE LA PEÑA, El hombre y su muerte, o.c, 89, nota 87.

118. «En definitiva, morir se manifiesta al Dasein como su posibilidad más insuperable (puesto que no puede ser evitada), las más personal (puesto que la muerte me reduce a mi puro mí mismo), la más irrelacional (puesto que me corta todas las relaciones con toda otra posibilidad»).

A. de WAELhens, o.c., 149.

119. Cfr. Hans Kung, ¿ Vida eterna?, Cristiandad, Madrid 1983, 73.

120. Cf. J.L. RuIz dE la PEÑA, El último sentido, Marova, Madrid 1980, 138.

121. Cfr. J.P. SARTRE, El ser y la nada, Losada, Buenos Aires 1972, 11-12. 
su vez, lo que es, lo es absolutamente, pues se muestra a ese alguien tal como es (no remite a una realidad nouménica). Sartre reemplaza la realidad de las cosas por la objetividad del fenómeno. Ahora bien, el objeto es infinito en cuanto que no se agota en las manifestaciones, en los aspectos bajo los que se revela el fenómeno del ser, la aparición del ser. Ese infinito, fundamento de todas las manifestaciones, es el ser. transfenomenal ${ }^{122}$, que se revela en la experiencia, y que como luego veremos, es el «en-sí». El «en-sí» es el ser de lo que aparece, la condición de la desvelación del fenómeno. Esta experiencia metafísica es para Sartre nauseabunda, pues nos revela la gratuidad y el absurdo del ser. Pero curiosamente, antes de dar una formulación conceptual, más formalizada y filosófica, nos pretendió comunicar su pensamiento, a través de la literatura ${ }^{123}$.

Una obra fundamental al respecto es su novela «La Náusea», en la que nos relata la extraña experiencia de Antoine Roquetin. Una experiencia que nos sitúa en presencia del ser y su misterio, y que nos revela lo que quiere decir «existir» ${ }^{124}$. Mientras clasificamos y usamos las cosas, vivimos en la superficie, y no tenemos la experiencia de la existencia. Esta última sólo se desvelará si superamos el nivel de las explicaciones y de las causas ${ }^{125}$. Es entonces cuando caeremos en la cuenta de que lo único que podemos decir de las cosas y de nosotros mismos, es que estamos y «estamos de más» ${ }^{126}$. Esto es, estamos sin

122. «Con ello, Sartre no trata de postular una 'ocultación' del ser tras el fenómeno, sino tan sólo mostrar el hecho de que 'el ser de lo que aparece' escapa, pura y simplemente, a la condición fenoménica que consiste en 'no existir más que en tanto que se manifiesta'». J.A. ARIAS MUÑoz, Jean Paul Sartre y la dialéctica de la cosificación, Cincel, Madrid 1987, 76-77.

123. Por eso escribe René Lafargue: «No es corriente acceder a la filosofía por vía de la novela. Sin embargo esıa posibilidad nos la ofrece Sartre en La Náusea». R. LAFARGUE, La filosofía de Jean Paul Sartre, G. del Toro, Madrid 1970, 27.

124. «Jamás había presentido antes de estos últimos días, lo que quería decir 'existir' (...). Pensaba en la pertenencia, me decía que el mar pertenecía a la clase de los objetos verdes o que el verde formaba parte de las cualidades del mar (...). Pero todo eso pasaba en la superficie. Si me hubieran preguntado qué era la existencia, habría respondido de buena fe que no era nada, exactamente una forma vacía que se agrega a las cosas desde fuera, sin modificar su naturaleza. Y de golpe estaba allí, clara como el día: la existencia se había desvelado de improviso. Había perdido su apariencia inofensiva de categoría abstracta; era la pasta misma de las cosas (...); la diversidad de las cosas, su individualidad sólo era una apariencia, un barniz. Ese barniz se había fundido, quedaban masas monstruosas y blandas, en desorden, desnudas, con una desnudez espantosa y obscena». J.P. SARTRE, La Náusea, Alianza-Losada, Madrid-Buenos Aires 1981, 163-164.

125. El saber y la ignorancia no tienen importancia con relación a la existencia, pues, «el mundo de las explicaciones y razones no es el de la existencia». La existencia está «por debajo de toda explicación». J.P. SARTRE, o.c., 166 y 167.

126. «De más: fue la única relación que pude establecer entre los árboles, las verjas, los guijarros (...)

Y yo -flojo, lánguido, osceno, dirigiendo, removiendo melancólicos pensamientos-, también yo estaba de más (...) de más para toda la eternidad». J.P. SARTRE, o.c., 166. Cfr. también 171 . 
explicación, sin razón posible, estamos absurdamente. El absurdo es algo fundamental y absoluto, sin relación a nada. La existencia es contingencia, gratuidad injustificable. Sartre termina su novela con esta tesis: «Todo lo que existe nace sin razón, se prolonga por debilidad y muere por casualidad» ${ }^{127}$. Y todo ello resulta nauseabundo, repugnante y estúpido ${ }^{128}$.

No obstante - como dijimos- es en su ontología fenomenológica, que desarrolla en «El Ser y la Nada», donde consigue una categorización más rigurosa de esta experiencia metafísica. Para Sartre se recortan dos realidades fundamentales: el «en-sí» y el «para-sí». El ser «en-sí» (ser transfenoménico del fenómeno) viene a ser las cosas materiales, entes masivos, increados, idénticos en su sólida plenitud. «El ser «en-sí» es lo que es», siendo completa positividad, y no estando sujeto a temporalidad ${ }^{129}$. El ser «en-sí» simplemente es, no siendo ni posible ni imposible. Esto es lo que quiere decir la expresión: el ser es superfluo, está de más. La conciencia no puede derivar el ser de nada, ni de otro ser, ni de una posibilidad, ni de una ley. Increado, sin razón de ser, sin conexión con otro ser. Es la facticidad bruta y gratuita ${ }^{130}$. «El ser es, sin razón, sin causa y sin necesidad; la definición misma del ser nos presenta su contingencia originaria» ${ }^{131}$.

Claro que el ser «en-sí» así descrito, no agota todo el ser. Frente a él, aparece la conciencia de esta experiencia metafísica (el hombre). La conciencia 0 ser «para-sí» surge en el seno del ser «en-sí». Y con relación a su ser transfenomenal, Sartre dirá que es siempre conciencia de algo (conciencia posicional), pues es intencionalidad abierta hacia; está constantemente proyectada fuera de sí misma, hacia objetos exteriores, siendo, pues, inseparable del ser «en-sí». La conciencia es huida de sí misma, deslizamiento fuera de sí, negación a ser sustancia.

127. J.P. SARTre, o.c., 172.

128. «Lo esencial es la contingencia. Quiero decir que, por definición, la existencia no es la necesidad. Existir es estar ahí simplemente: los existentes aparecen, se dejan encontrar, pero nunca es posible deducirlos (...), ningún ser necesario puede explicar la existencia, la contingencia (...) es lo absoluto y en consecuencua la gratuidad perfecta. (...) Cuando uno llega a comprenderlo, se le revuelve el estómago y todo empieza a flotar (...); eso es la náusea». J.P. SARTRE, o.c., 168-169.

129. «Es, y, cuando se derrumba, ni siquiera puede decirse que ya no sea más. (...) él mismo no existe, como algo que falta allí donde antes era (...) Él era, y ahora otros seres son: eso es todo». J.P. SARTRE, El ser y la nada, o.c., 36.

130. Cfr. J.P. SARTRE, El ser y la nada, o.c., 36. Tiene razon Laín cuando afirma que en Sartre no encontramos una "ontogenia», pues el ser "en-sí» no tiene origen. Lo que Sartre desarrolla es una antropogonía y una antropodicea, en la medida en que describe el origen del para-sí, e intenta una justificación del mismo. Cfr. P. Laín EnTralgo, La espera y la esperanza, o.c., 217.

131. J.P. SARTRE, o.c., 750. 
Como dice Sartre, la conciencia estalla hacia el mundo, pero sin coincidir nunca con él. Yo no puedo afirmar algo más que a condición de no serlo ${ }^{132}$. Si el ser «en-sí» es el reino de la identidad, la conciencia es desdoblamiento y no coincidencia plena consigo misma; surge como nihilización del «en-sí». Sostiene a la nada al determinarse como una falta de ser, como el no ser del «ensí». La negación afecta a la estructura interna de su ser. La conciencia es pues, el ser por el que la nada viene al mundo, como una especie de agujero en el ser compacto. $\mathrm{Y}$ es fundamento de sí como defecto de ser, al hacerse determinar en su ser por un ser que no es ella ${ }^{133}$.

Además, la subjetividad como ser transfenomenal del sujeto, no es sino libertad ${ }^{134}$. El ser «en-sí», lleno de sí mismo, no es libre en su plenitud compacta. En cambio, el hombre es libre, pudiendo separarse de sí mismo y del mundo, e interrogarse. El hombre es libre en sus emociones, pasiones y actos voluntarios. Su libertad le da capacidad para elegir los medios, los fines, y crear valores. El valor como ideal lo hace surgir la libertad, y lo mantiene o lo destruye, según le place, sin excusas ni recursos posibles. La libertad es, pues, decisión gratuita e injustificable, al estar más allá de toda razón. En este sentido, la existencia precede a la esencia ${ }^{135}$, y el hombre se define después, des-

132. Para Sartre conocer una cosa es saber que no se es tal cosa. La conciencia es un poder «de no ser lo que se es, y de ser lo que no se es»: ella no cobra conciencia de sí misma más que cuando está asentada u orientada sobre un objeto que no es ella misma, y por otro lado, es lo que no es, ya que conoce nihilizando el ob

133. «El hombre es el ser por el cual la nada adviene al mundo». J.P. SARTRE, o.c., 66. Además, el ser para-sí está presente a sí mismo, lo que supone un desprendimiento de parte del ser en relación a sí mismo, la apertura de una impalpable fisura en el ser. La presencia presupone la separación del sujeto de sí mismo, y esto es la nada. Cfr. J.P. SARTRE, o.c., 128-129. La conciencia, como fundamento del movimiento de trascendencia que es su intencionalidad es «conciencia de conciencia» o conciencia de sí misma. Y esto no entendido como un conocimiento reflexivo (lo cual supondría una escisión en la conciencia y un proceso de desdoblamiento del sujeto y objeto al infinito), sino como una relación inmediata de sí a sí de la conciencia. Mientras que en Heidegger, la nada aparece como el último horizonte metafísico, para Sartre es una «secreción del ser». Y la conciencia existe por sí, es causa de su manera de ser, sacándose del ser.

134. «El hombre es libre porque no es sí mismo, sino presencia a sí. El ser que es lo que es no puede ser libre. La libertad es precisamente la nada que es asida en el meollo del hombre y que obliga a la realidad humana a hacerse en vez de ser (...) para la realidad humana ser es elegirse (...) la libertad (...) es el ser del hombre, es decir, su nada de ser». J.P. SARTRE, o.c., 546.

135. «El acto decide de sus fines y sus móviles, y el acto es expresión de la libertad. (...) Pero la libertad no tiene esencia. No está sometida a ninguna necesidad lógica. (...) 'En ella la existencia precede y determina a la esencia'». J.P. SARTRE, o.c., 542-543. En el mundo de los objetos fabricados «se puede decir que la producción precede a la 'existencia'. Frente a ello 'hay por lo menos un ser en el que la existencia precede a la esencia, un ser que existe antes de poder ser definido por ningún concepto, y que este ser es el hombre o, como dice Heidegger, la realidad humana. El hombre (...) empieza por no ser nada. Sólo será después, y será tal como se haya hecho. Así, pues, no hay naturaleza humana». J.P. SARTrE, El existencialismo es un humanismo, Sur, Buenos Aires 1973, 15 y 17. Cfr. también 37, 56-57. 
cansando su decisión en sí mismo de un modo absoluto ${ }^{136}$. La conciencia es, pues, nihilización, trascendencia y libertad.

Desde luego el hombre está condicionado por una serie de circunstancias (desde sus apetitos, a su familia, clase, etc.), pero todo ello, dirá Sartre, es un medio para la realización de su libertad, entendida como autonomía de elección, que posee un comienzo de realización, aunque su acción no siempre llegue al éxito ${ }^{137}$.

Con la conciencia-libertad se constituye el pasado como relación original y nihilizante del «para-sí» al «en-sí». El pasado es el «en-sí» siempre creciente que somos. Un pasado irremediable. Y cuando muramos sólo seremos eso ${ }^{138}$. No obstante, mientras vivamos, podremos asumir la facticidad del pasado, y darle un sentido convirtiéndola así en un medio para el ejercicio de mi libertad.

Según Sartre, somos responsables de nuestra existencia, y nuestra responsabilidad no tiene límites; se extiende al mundo cuyo peso soportamos, ya que al elegirnos a nosotros mismos, elegimos todos lo que nos rodea. $Y$ el hombre se angustia cuando toma conciencia de su libertad y su nada, cuando se sabe solo y sin ayuda, sin posibilidad de proyectar su responsabilidad sobre algo (mala fe) ${ }^{139}$.

La naturaleza y extensión del presente trabajo nos impide extendernos exhaustivamente sobre una reflexión crítica de la ontología fenomenológica de

136. «Pero si verdaderamente la existencia precede a la esencia, el hombre es responsable de lo que es». «Estamos solos, sin excusas. Es lo que expresaré diciendo que el hombre está condenado a ser libre. (...) el hombre sin ningún apoyo ni socorro, está condenado a cada instante a inventar al hombre». «recordamos al hombre que no hay otro legislador que él mismo, y que es en el desamparo donde decidirá de sí mismo». J.P. SARTRE, El existencialismo..., o.c., 19, 27-28 y 64.

137. Incluso un preso - dice Sartre - puede proyectar su evasión y mostrarse el valor de este proyecto por medio de un comienzo de acción.

138. «En el límite, en el instante infinitesimal, 'de mi muerte, no seré ya más que mi pasado. Él sólo me definirá (...) Por la muerte, el para-sí se trueca para siempre en en-sí en la medida en que se ha deslizado íntegramente al pasado». J.P. SARTRE, El ser y la nada, o.c., 169. Cfr. también 660 .

139. Cfr. J.P. SARTRE, El ser y la nada, o.c., 91 ss. La mala fe o «el mal ontológico de la conciencia» es pretender que uno ha nacido con un ser determinado, en vez de reconocer que nos pasamos la vida intentando hacernos a nosotros mismos». Cfr. J.P. SARTRE, El existencialismo, o.c., 22 ss, 40 y 56 . No debemos de confundir la mala fe con la mentira: «mientras que para la mentira hay una dualidad engañador-engañado, en la «mala fe» esa dualidad se ha unificado en la misma persona, en mí, que soy, a la vez, el engañador y el engañado». J.A. ARIAS MUÑoz, o.c., 100. En esta tarea de autoconquista libérrima, el hombre se revela como una «pasión inútil». En todo proyecto lo que el hombre intenta es salvar su carencia de ser. El hombre desea ser fundamento de sí mismo, pero llegando a ser el en-sí que no es. Desea llegar a ser «ens causa sui». Pero un «en-sí-para-sí» es una contradicción imposible. Cfr. J.P. SARTRE, El ser y la nada, o.c., 690$691,747,751,754-755$. 
Sartre (y de Heidegger) ${ }^{140}$. Lo que nos interesa destacar, no obstante, es, en el contexto de este proceso libre de autorrealización significante para-sí, que

140. Todo el planteamiento sartreano está condicionado por una intuición metafísica: la repulsa del ser. Un ser que se capta como opaco, indiferente y gratuito. La conciencia que interroga y conoce, no podrá existir más que separándose de la positividad del ser. Así, la filosofía de Sartre sobre la nada y los valores es una consecuencia de su ontología. Claro que su descripción fenomenológica nos resulta discutible. Como dice Hans Küng parece más una imprecación que una fundamentación.

Pensamos que, frente a la fenomenología sartreana, cabe otra ontología que destaque la contingencia de los seres. A partir de aquí es posible postular la religación que da consistencia y sentido a la realidad óntica. Cabe una interpretación metafísica que abarque a todos los entes y que busque una causa y un sentido más allá de la conciencia y libertad humanas, aunque se revele y anuncie a través de ellas. Esto implica, naturalmente, la captación del contenido analógico del concepto de ser.

Nosotros ante la realidad decimos: esto es. Los árboles son, los animales son, los hombres son, etc. El decir que la realidad es, es interpretar la realidad e interpretarnos a nosotros mismos. El ser parece ser - como ya dijimos - la máxima interpretación humana de la realidad. Pero, ¿qué alcance, qué significación implícita tiene esto? Los entes son, y al decir esto nos referimos a aquellas realidades objetivas, que tienen una consistencia, un modo de ser que permanece de algún modo a través del tiempo. Y como Heidegger, intentaremos profundizar en el del ser que el ente presupone. (Precisamente lo que Heidegger pretendió con su método fenomenológico, entendido como actitud critico-hermenéutica, fue sacar a la luz lo que está presente, pero se oculta en el ente como su sentido y fundamento: el ser).

¿El ente agota el ser? Evidentemente un ente no agota el ser, pues si no, sólo existiría ese ente. (En ese sentido queremos entender la afirmación de Heidegger de que el ser no se puede concebir como un ente, o que el ser del ente no es él mismo un ente). Diríamos que en los entes, en las sustancias que conocemos, se hace presente el ser, pero sin agotarlo. El ente es como una «ventana» por la que podemos «asomarnos» al ser, pero donde nunca es definitivamente objetivado. Lo que se objetiva es el ente, una modalidad del ser. En este sentido es clara la diferencia ontológica establecida por Heidegger entre ser y ente. El ser no puede ser pensado como una cosa u objeto. De momento hay que entenderlo como el horizonte de significado, el transfondo sobre el que el ente se recorta y entiende, lo que hace que algo comparezca como siendo. El ser, pues, nunca es captado en su totalidad, claramente demarcado y explicitado en su intima naturaleza. Algunos piensan: un ente no agota el ser, pero los entes son momentos, manifestaciones objetivas del ser; y el conjunto de todos los entes manifiesta lo que es el ser, viene a ser la objetivación del ser, la explicitación de su íntima naturaleza en toda su riqueza. El «mundo» es el ser expresado y objetivado. ¿Pero realmente se puede admitir esto tan fácilmente?

El ser es por sí mismo, si el ser fuese por otra cosa, ella estaría dentro de él, porque el ser agota toda realidad. El ser es razón de sí por su absolutez. En cambio los entes, cada ente, no muestra la razón de sí en su propia esencia. Los entes son contingentes, son y desaparecen. Podríamos decir que todos son gracias al ser, pues todos son manifestaciones suyas. Ahora bien, si ningún ente es por sí mismo, el conjunto de ellos tampoco encierra en sí la razón de ser. Y si el conjunto de los entes se identificase con el ser, llegaríamos a la conclusión de que el ser no sería razón de sí mismo. Luego parece que hay una diferencia entre el ser y el conjunto de los entes.

No obstante, alguno podría decir: el ser es razón de sí en cuanto que es idéntico consigo mismo, pero en cuanto que está relativizado en sus momentos manifestativos, oculta su necesidad en la pluralidad. ¿Pero no es esto un discurso forzado y oscurantista? ¿No parece más bien, que el ser no puede identificarse, sin más, con el conjunto de los entes? Lo que vemos claro es que el ser es el horizonte donde se mueven los entes, sin agotarlo. Es más, pensando en el conjunto de los entes, éste se nos manifestará como un todo relativo al ser, y por tanto siempre podremos pensar 
constituye la vida del hombre, el juicio que merece para Sartre la perspectiva y el hecho de la muerte.

que hay un «hueco» sin llenar. Hay una distancia entre lo relativo y lo absoluto, que nada relativo puede salvar. Podemos pensar infinitos entes sin agotar el ser.

Salvando la actitud de quienes afirman, sin más, la gratuidad del ser (y por tanto su absurdo), se nos dibujan pues, dos interpretaciones del problema metafísico. Una interpretación es la que mantiene que el ser se ha degradado, se ha objetivado en los entes, y para que sea en perfección deben todos los momentos «diluirse» de nuevo en la Única Realidad. Es la mística de Oriente con todo su pesimismo metafísico. La realidad óntica es degradación, imperfección, dolor y miseria. El cosmos y el hombre deben reintegrarse en el Ser o la Nada (nada de lo que es ente, nada como negación de la cosa), ascender por disolución, hasta la pérdida de sí y la afirmación del Todo Indeterminado. La raíz del mal está en la individuación. Es también, de algún modo la «mística» del idealismo alemán (ahora sin pesimismo): el Ser, la Nada o la Idea se despliega, se aliena para volver a reencontrarse, enriquecido en el Espíritu Absoluto. Pero todo «panteísmo» o «monismo metafísico» muestra, a mi modesto juicio, una debilidad: no se enfrenta satisfactoriamente al problema al que antes hemos aludido: el «hueco» existente entre el ser y el ente. Pueden decirnos que, en último término, el panteísmo no identifica absolutamente el Ser y el ente; reconoce el «hueco», en la medida en que habla de degradación, de alienación del Ser. Pero entonces me pregunto ies que lo Absoluto, lo Perfecto, en su Identidad y Plenitud, puede tener degradaciones, imperfecciones? ¿No son categorías radicalmente antitéticas, que ninguna dialéctica puede sintetizar sin forzar el discurso metafísico? Por ello todo monismo o panteísmo se me aparece como una «metafísica de la ambigüedad». (Recordemos la doctrina de los modos y atributos de Spinoza). Cabe hablar de contradicciones y relaciones dialécticas en el mundo de lo relativo (de lo óntico), pero en el plano del Ser (de la afirmación absoluta), lo primero que se impone es la identidad positiva, incondicional, absoluta.

La otra interpretación del problema metafísico es la que niega la identificación del cosmos y el Ser. ¿Pero si los entes no son manifestaciones u objetivaciones del Ser, qué son en definitiva? He aquí la respuesta: los entes no son el Ser, ni emanaciones suyas. ¿Y qué es eso de la «creación»? Crear es dar el ser. ¿Pero si el Ser da el ser, no da algo suyo, no se da a sí mismo». ¿Y no es esto, otra vez, el panteísmo? Sólo cabe decir que el Ser da el ser pero sin pérdida de sí, entendida como degradación o desposesión de su íntima naturaleza. El ente participa del ser sin detrimento del Ser. (Y nótese que ahora hablo de «ser» y de «Ser». El primero es un vocablo que abarca conceptualmente a los entes y al Ser. En su universalidad es un vocablo analógico).

Todo esto nos puede llevar a pensar que el «ser» es entonces algo más rico, «más ser» que el «Ser». Pero esta conclusión es gratuita, porque el Ser no es connumerable con los entes. Y aquí hay que mantener un difícil equilibrio. En cuanto que se mantiene la analogía del ser, Dios o el Ser no es contradistinto de todos los demás entes. Pero en cuanto que es inobjetivable e indeterminable es el Misterio, «lo Totalmente Otro». Es la Trascendencia con relación a la inmanencia, que es obra suya. Insistiendo en este último aspecto y teniendo «in mente» el ser de los entes, Jankélévitch denomina al Creador el «sobre ser» o lo «hiperóntico». «... el que da o confiere no es él mismo lo que da, ni lo posee previamente para luego darlo (como un propietario que dona sus propiedades); no se puede incluso decir que lo posee en primer lugar para luego darlo, lo da antes de poseerlo, y lo hace ser en el acto mismo por el que lo dona; ¡literalmente da lo que no tiene! El hacedor del ser no tiene él mismo ser, puesto que crea el ser, y lo crea dándolo». V. JANKélévitch, o.c., 67. «Así Dios no es, en el sentido óntico del verbo ser». (o.c., 68).

Desde esta interpretación del misterio del ser que aporta la categoría de «creación», podemos seguir diciendo que los entes son la «ventana del Ser», pero esta expresión (como el término «presencia»), cobra una nueva precisión. Los entes son ahora la «ventana del Ser», pero análogamente a como una obra de arte es presencia del hombre. Podemos decir que «el ente es la obra de arte del Ser». Y ahora sí se alumbra una dialéctica de la inmanencia y la Trascendencia. La primera es «presencia» de la segunda, que se revela como fuente creativa de aquélla. Sólo desde aquí creo 
Nuestro autor señala que si consideramos la muerte del «otro lado», aparece como lo inhumano, «como adherente a la nada del ser que limita el proce-

que cobra cierta coherencia el misterio del ser. Y ello siendo consciente de que todo intento de racionalización resulta insuficiente. ¿Podremos comprender en su íntima naturaleza el acto creador?, ¿o la coexistencia del Infinito con los entes finitos? Aquí hay que recordar que aunque a la idea de «creación» se puede llegar por un discurso racional como el aquí planteado, originariamente es una idea religiosa o revelada. En la cultura occidental esta idea es de origen bíblico, y está unida al modo cómo Israel concibió a su Dios. Un Dios que sobre todo aparece como protagonista de una historia de salvación, y en función de esa salvación va apareciendo como dominador y señor del mundo. De tal modo, que teológicamente hablando, el concepto primario no es tanto el de «creación» como el de «Alianza». La primera idea está implícita en la segunda: ¿Si Yahvé lo puede todo, no será porque lo ha hecho todo? Y serán los profetas exílicos los que la explicitarán (Jeremías, Deuteroisaías, etc.). Se usa en estos textos un término técnico bara, para aludir a la acción creadora exclusiva de Yahvé. En ella «... nunca se menciona una materia ex qua, un instrumento o una colaboración; su énfasis recae sobre el carácter de novedad inédita de lo creado (...). Designa, pues, una acción incomparable, no homologable a ninguna otra, específicamente divina, al contrario de lo que ocurre con otros verbos como hacer, modelar, formar, etcétera, que pertenecen al vocabulario artesanal». Además «se aplica tanto el hablar de objetivos cósmicos (...) como tratando de realizaciones histórico-salvíficas». J.L. RuIz DE LA PEÑA, Teología de la creación, Sal Terrae, Santander 1986, 29 y 30. Y es que bara «implica tanto la idea de dar principio a una realidad como procurar su consumación. Esta idea encontrará una formulación en el texto del Génesis que es contemporáneo de los textos proféticos. Con el término bara se apunta, pues, la idea de «creatio ex nihilo» que irán madurando los padres apologistas, y que desarrollará la filosofía medieval. Añadamos que Dios confiere el ser a las cosas por su palabra, lo que indica la condición dialógica de la relación creador-creatura. La creación de este modo es, por parte de Dios, «alocución comunicativa» y «comienzo de la historia salvífica». Así, «el mundo viene a ser 'expresión' de Dios, lo que resulta de su dicción», J.L. RuIZ DE LA PEÑA, o.c., 41. Esta verdad revelada arroja luz sobre mi concepción del ente como «obra de arte del Ser». Y otra profunda verdad de fe, que enriquece nuestra ontología es que el Dios bíblico crea por su palabra «en virtud de su libérrimo designio de autocomunicarse. El amor, no el poder, se revela así como la genuina urdimbre de lo real», J.L. RUIZ DE LA PEÑA, o.c., 47.

Digamos también, que analizando la estructura de nuestro lenguaje, vemos que el objeto de nuestra afirmación es el ente. Nosotros decimos «esto es tal cosa». En esta afirmación aplicamos al «bloque existencial no analizado» (esto) una modalidad, una cualidad, y ello gracias a la misma afirmación (es). Lo que indigitamos (esto), que es el objeto de nuestra afirmación, nunca agota al ser, sino que se mueve, como hemos dicho, en ese horizonte de la afirmación, del ser. Según esto, la afirmable humanamente es el ente. Pero entonces ¿es que el Ser no es afirmable? Aquí sólo nos queda una solución, que precisamente desechó Heidegger, la analogía. Sobre todo el «segundo Heidegger» que intentó una posterior elaboración de la cuestión del ser al margen de una fílosofía de la subjetividad» o de «iluminación» en sí mismo, y no como manifestabilidad de los entes. El ser será entonces un acontecer que se retrae cuando se manifiestan los entes. En este sentido el ser es para Heidegger «ausencia». No obstante creemos que si el Ser se oculta en los entes, también se presencializa y se sugiere en ellos. La ausencia del Ser denota su infinitud y absolutez. Una experiencia directa del Ser exigiría su imposible objetivación. No obstante, creemos que a través de la analogía, y con la toma de conciencia de la insuficiencia de nuestro lenguaje «entificador», se puede apuntar hacia esa trascendencia misteriosa del Ser repecto del ente, en el que, a pesar de todo, se hace presente. Presencia que se ilumina con el concepto de «creación». Con la analogía apuntamos hacia una Realidad que, en último término, siempre se nos escapa. (Cfr. J. GómEZ Caffarena, o.c., $361 \mathrm{ss}$ ).

El intento que el segundo Heidegger deja abierto: pensar el ser desde sí mismo, sin referencia al ente (Cfr. Carta sobre el humanismo, o.c., 31-32), (lo que significa para él la superación de una 
so». Pero si la consideramos como un acaecimiento de la vida, parece revelársenos como lo que pone término a un proceso existente, incidiendo en su significación ${ }^{141}$. Desde esta perspectiva se intenta interiorizar la muerte, ha-

cierta metafísica de la subjetividad, cuyo máximo exponente fue el nihilismo de Nietzsche - voluntad de poder-y su realización moderna la técnica), creo que es un camino sólo para privilegiados: místicos o iluminados. Incluso los términos utilizados por nuestro filósofo recuerdan más el lenguaje propiamente religioso, que el estrictamente filosófico (escucha, acogimiento, dejar ser, espera...).

Habiendo identificado el misterio del ser con el misterio de Dios, podemos, incluso hacer una última puntualización. Y es que la pregunta por el sentido de la realidad que, en último término, se abre al misterio del Ser-Dios, no puede dejar al margen al sujeto que la formula: el hombre. Tiene que ver con sus exigencias de inteligibilidad y sus necesidades más profundas. Y en la medida en que la pregunta es humana, también tiene que serlo la respuesta. Un margen de «antropomorfismo» es inevitable, incluso para la Revelación. Sabemos que el Ser es inobjetivable, que está más allá de la relación sujeto, objeto (Heidegger), y no obstante en la medida en que lo pensamos y en que se nos revela, lo concebimos y lo pensamos como Sujeto Supremo, Inteligencia Suma, y Persona Absoluta. Si no fuera así, no tendría sentido para nosotros. Ello es válido si sabemos, a su vez, de la insuficiencia de todo abordaje humano del Misterio.

Por otro lado, el vocablo con el que Sartre denomina a la conciencia es un tanto dudoso. $\mathrm{Si}$ con ello queremos decir que la conciencia es una cierta objetivación de la realidad, una tendencia hacia lo que se carece, y un desdoblamiento de su propia realidad (un «dentro» o «interior»), estamos de acuerdo. Pero si el término quiere decir que la conciencia no sea, con un carácter antitético en relación a la realidad preconsciente, no se ve tan claro. ¿Es que las tendencias del hombre, su capacidad de conocimiento, de elección, de comunicación y de transformación del mundo, no revelan una densidad óntica, aunque superior a la del mundo objetivable? Lo que sí es cierto es que no será de la misma manera que son los entes premorales. «... en la especulación sartreana todo procede de un supuesto fácilmente concedido y no tan fácilmente justificable. Me refiero a la absoluta negatividad de la conciencia. (...) En la autoconciencia se revela una realidad, más aún, la «realidad radical»: Realidad y conciencia coinciden en ese comienzo». Teniendo en cuenta el dinamismo que nos constituye, «debemos más bien admitirnos como una realidad rica e indigente al mismo tiempo». J. Gómez CAFFARENA, , o.c., 201. En esta misma línea cuestionamos la tesis sartreana de que la existencia sea anterior a la esencia. Para Sartre no hay naturaleza humana, sólo libertad. Nuestro autor es uno de los máximos exponentes de la noción moderna de libertad: «Para la conciencia moderna la libertad es la potestad de poseer lo que previamente se ha elegido. No hay conexión directa entre libertad y verdad. Esta no tiene que ser buscada y acogida sino que es resultado del ejercicio del poder. Se la constituye decidiéndola». O. González DE CARDEDAL, o.c., 26. No obstante pensamos que de algún modo siempre «somos hombres». Encontramos un dinamismo teleológico definidor de lo humano. El hombre es deseo de conocer, de transformar, de amar. Todo ello compatible con una plasticidad congénita llamada a desplegarse en las diversas soluciones que son las distintas culturas y civilizaciones. Por tanto, «La libertad se tiene cuando se posee la fuerza necesaria tanto para reconocer el bien como para quererlo y realizarlo». O. GoNZÁlez DE CARDEDAl, o.c., 25. En este sentido la naturaleza humana no se opone, sino que integra a la libertad. Lo que ocurre es que Sartre no distingue entre la «esencia universal» que nos hace hombre, y la esencia individual que nos hace este hombre determinado. La primera presenta una relativa indeterminación, una plasticidad, que, en el fondo, encierra una llamada a la tarea libre y responsable de la propia vocación. Frente a Sartre, pensamos que hay un ser transituacional que orienta la acción particular, aunque no la determina de un modo unívoco.

141. Sartre compara a la muerte con el acorde final de una melodía: «Así, el acorde final de una melodía mira por una faz hacia el silencio, es decir, hacia la nada de sonido que seguirá a la melodía; en cierto sentido está hecho con silencio puesto que el silencio que seguirá está ya presen- 
cerla propia: «se convierte en el sentido de la vida, como el acorde de resolución es el sentido de la melodía» ${ }^{142}$. Este fue el intento de humanización de la muerte llevado a cabo por Heidegger. Pero Sartre no está de acuerdo con él: admitiendo el carácter absurdo de la muerte, hace notar que «toda tentación de considerarla como un acorde de resolución al término de una melodía debe ser rigurosamente apartada» ${ }^{143}$. Tampoco es viable para nuestro autor la resuelta decisión heideggeriana de esperar la muerte. Puedo esperar una muerte particular, pero no la muerte en general. Sólo se puede aguardar un acaecimiento determinado - dice Sartre. Pero éste no es el caso de mi muerte, que está condicionada por una infinidad de factores o variables indeterminables. Las únicas excepciones serían la muerte por vejez y por condena explícita ${ }^{144}$. Pero lo propio de la muerte es que puede sorprendernos. Además la muerte es la aniquiladora de todas mis posibilidades: ella «no puede ser captada como mi posibilidad, sino, al contrario, como la nihilización de todas mis posibilidades, nihilización que no forma parte ya de más posibilidades. Así, la muerte no es mi posibilidad de no realizar más presencia en el mundo, sino una nihilización siempre posible de mis posibles, que está fuera de mis posibilidades» ${ }^{145}$.

La vida humana es significante, haciéndose anunciar por lo que es por venir; en este sentido la vida anuncia su significado prefigurando en su compromiso con un futuro. El pasado «toma del presente su sentido»; y es en él donde éste se ratifica o se transforma ${ }^{146}$. De ahí la necesidad de esperarnos a nosotros mismos. Todo ello descansa en la temporalidad del para-sí. Nuestra vida es una cadena de esperas. Ahora bien, «Todas esas esperas comportan, evidentemente una referencia a un término último que sea esperado sin que espere nada a su vez. Un reposo que sea ser y no ya espera de ser. Toda la serie está suspendida de este término último (...) que es al valor de nuestro ser» ${ }^{147}$. Es el término que me define y fija mi vida. Pero esta interpretación de la muerte, desde el punto de vista del «status viatoris», a la que aludimos en nuestra ex-

te en el acorde de resolución como significación de éste; pero por la otra faz, se adhiere a ese plenum de ser que es la melodía final considerada: sin él, la melodía quedaría en el aire, y esta indecisión final se remontaría contra corriente, de nota en nota, para conferir a cada una de ellas un carácter inconcluso». J.P. SARTRE, El Ser y la Nada, o.c., 650. Cfr. también Y. JANKÉLEvitCh, o.c., 119 .

142. J.P. SARTRE, o.c., 651.

143. J.P. SARTRE, o.c., 652.

144. Cfr. J.P. SARTRE, o.c., 655.

145. J.P. SARTRE, o.c., 656. Cfr. también E.M. CIORÁN, o.c., 58, 62-63, 117, 118 y 193.

146. «... el adolescente es perfectamente consciente del sentido místico de sus conductas y a la vez debe remitirse a su futuro íntegro para decidir si está «pasando por una crisis de pubertad o si está encaminándose definitivamente hacia la devoción». J.P. SARTRE, o.c., 657.

147. J.P. SARTRE, o.c., 657. 
posición, es cuestionada por Sartre. En la medida en que la muerte nos es da$\mathrm{da}$, esto es, no descansa en nuestra propia libertad, arrebata a la vida toda significación: «Si hay espera de esperas de espera y si, de golpe, el objeto de mi espera última y el mismo que espera son suprimidos, la espera recibe retrospectivamente carácter de absurdo» ${ }^{148}$. Desde su temporalidad, el para-sí reclama siempre un después significante ${ }^{149}$. Pero... «¿Qué podría significar, entonces una espera de la muerte, sino la espera de un acontecimiento indeterminado que reducirá toda espera a lo absurdo, incluida la de la muerte? La espera de la muerte se destruiría a sí misma, pues sería negación de toda espera» ${ }^{150}$. La muerte no puede ser una posibilidad para el hombre, ni pertenece a su estructura ontológica ${ }^{151}$. La muerte es sólo un acontecimiento aniquilador.

Claro que sobre una vida muerta, con toda su carga de absurdidad, puede jugar la «memoria del otro», intentando custodiarla. El otro puede reconstruir la vida del muerto. Por tanto, la actitud de los vivos juega sobre los muertos. $Y$ es que el «ser-para-otros» del «ser-para-sí» también afecta a los muertos. El hombre al proyectarse decide, entre otras cosas, sobre la importancia de los que le precedieron (de sus empresas), sean allegados o meros próximos ${ }^{152}$. En este sentido, la vida muerta, «tampoco cesa de cambiar, pero no se hace, sino que es hecha» ${ }^{153}$.Claro que ella no será ya la responsable de la ratificación o modificación de su sentido; esto último le vendrá del exterior. El muerto es desposeído de su ser y sentido, que es asumido por los otros vivos. $Y$ esto significa que «el que intenta captar el sentido de su muerte futura debe descubrirse como futura empresa de los otros» ${ }^{154}$. Así, la muerte no solamente es la supresión definitiva de mi espera, «sino que también confiere un sentido desde fuera a todo cuanto vivo en subjetividad» ${ }^{155}$. Por tanto, y a la postre, se dará una privación de la significación subjetiva «para entregarla a cual-

148. J.P. SARTRE, o.c., 659.

149. En este sentido la vida es un trascender continuamente las situaciones concretas y las conquistas particulares. Es un rebasamiento siempre en marcha. Por ello escribe Jankélévitch: «Por viejo que sea uno, se muere siempre demasiado temprano; pues no hay en este sentido más que fines prematuros». V. JANKÉLEvITCH, o.c., 20. Hay, en este sentido, una contradicción entre nuestros anhelos más profundos, siempre insatisfechos, y nuestra estructura finita.

150. J.P. SARTRE, o.c., 660.

151. Cfr. J.P. SARTRE, o.c., 660 y 665 .

152. Basta que pertenezcan a la misma colectividad histórica concreta, dice Sartre...

153. J.P. SARTRE, o.c., 663.

154. J.P. SARTRE, o.c., 664.

155. J.P. SARTRE, o.c., 665. 
quier significación objetiva que al otro le plazca darle» ${ }^{156}$. Esta contingencia radical, significa «la metamorfosis de nuestro ser en destino» ${ }^{157}$.

Por todo ello y resumiendo, Sartre concluye frente a Heidegger, «que la muerte, lejos de ser mi posibilidad propia, es un hecho contingente que, en tanto que tal, me escapa por principio y pertenece originariamente a mi facticidad. No puedo ni descubrir mi muerte, ni esperarla, ni adoptar una actitud hacia ella, pues mi muerte es lo que se revela como lo indescubrible, lo que desarma todas las esperas (...) cuyo sentido está confiado para siempre a otros que nosotros. La muerte es un puro hecho como el nacimiento; nos viene desde afuera y nos transforma'en afuera» ${ }^{158}$.

Ciertamente toda la reflexión de Sartre sobre la reinterpretación de la vida del que ha muerto por parte de los que le han sobrevivido, está condicionada por su concepción pesimista sobre las relaciones con el otro (una dialéctica de la cosificación). Sin dejar de señalar lo unilateral de su planteamiento, hay que reconocer que dibuja un esquema teórico, que puede ser útil para analizar tantas manipulaciones de lo que la sociología de la muerte ha llamado el «muerto fecundo». (Baste este apunte sobre un tema que desborda los márgenes del presente trabajo).

Sartre tampoco está de acuerdo con la identificación heideggeriana de muerte y finitud. La muerte es una contingencia fáctica, mientras que la finitud «es una estructura ontológica del para-sí que determina a la libertad» ${ }^{159}$. Elegirse es ser finito.

A pesar de todo, al final, Sartre intenta una superación de este negro panorama, que nos recuerda el argumento epicúreo. La muerte, en el fondo, no lesiona a nuestro yo, a nuestra libertad, que permanece «total e infinita». La muerte al no ser realizable, no es ni una posibilidad mía, ni obstáculo a mis proyectos. Sartre concluirá que no soy libre para la muerte, sino simplemente mortal. Esto es, la muerte que deviene por añadidura, acaba alienando mi proyecto.

Respecto a la confrontación Heidegger-Sartre, tenemos que decir lo siguiente. Heidegger realiza un análisis de la muerte desde la vida; y desde esa perspectiva, tiene razón al señalar que la muerte se dibuja como una posibilidad que necesariamente tenemos que tener presente en nuestro proyecto, para que se alumbre una existencia auténtica. En este sentido, con Scheler y Hei-

156. J.P. SARTRE, o.c., 665 .

157. J.P. SARTRE, o.c., 666.

158. J.P. SARTRE, o.c., 666.

159. J.P. SARTRE, o.c., 667. 
degger, reconocemos a la muerte como parte de nuestra estructura ontológica, que testimonia nuestra condición finita. La exteriorización de la muerte sin más, que Sartre defiende, nos parece un intento forzado, que violenta el contenido del análisis fenomenológico. La muerte es evidentemente una amenaza para nuestros proyectos desde el lado de acá de la existencia, afectando, pues, a mi libertad de proyectarme y realizarme. (Cosa que a la postre, Sartre acaba reconociendo en su discurso) ${ }^{160}$.

Lo acertado de la crítica sartreana al planteamiento de Heidegger, está a nuestro juicio, en cuestionar su intento de asumir el proyecto de «estar a la muerte», como la posibilidad más radical y fundamental del hombre. Su intento de hacernos ver la necesidad de asumir la propia muerte como condición de una existencia auténtica, queda «herido de muerte» por el horizonte de nihilismo en que se sitúa. (Una especulación óntica sobre el más allá de la muerte queda fuera de su planteamiento).

La contraposición Heidegger-Sartre nos ayuda a destacar una de las paradojas de la muerte. Por un lado la muerte se refiere, de alguna manera, a la vida, como posibilidad inscrita en ella y «culminación» de la misma; y por otro lado, aparece como lo más exterior a la vida, siendo su propia negación. Quizás la única manera de percibir la verdad de las afirmaciones de estos dos filósofos, sea intentar asumirlas en una tensión dialéctica. Y en esa tensión, la muerte acaba mostrándosenos como una realidad tremendamente trágica, pues cuestiona radicalmente el sentido de la existencia y de la libertad. Y el futuro histórico no se nos aparece como un consuelo suficiente, ante la pérdida de la existencia personal.

La muerte como desposesión nos revela nuestra última no coincidencia con nosotros mismos, el que no nos poseemos radicalmente. Como dice Gevaert, con la muerte realizamos la experiencia de que no estamos en la raíz de nuestra propia vida, de que ni somos el fundamento de nosotros mismos, ni la norma última de los valores. ¿Esto no nos está diciendo también que la vida es un «don»? ¿Y la posible condición de criatura, como los límites y sufrimientos del hombre no pueden ser una invitación a reflexionar sobre la posible dimensión trascendente de la existencia humana, sobre su posible apertura al Misterio? Debemos de seguir, pues, profundizando en las condiciones del mo-

160. La exteriorización epicúrea, que en último término lleva a cabo Sartre, le sirve para proclamar una «soberana» libertad que, a pesar de todo, queda en suspenso y transida de sinsentido último. Su subjetivismo voluntarista (concepción moderna de la libertad) rezuma un nihilismo, que impide una fundamentación coherente de la ética. Es una libertad inútil. Al humanismo sartreano sólo le queda la afirmación incondicional de la libertad, con el trasfondo de un horizonte último de fracaso, garantizado por el proyecto inútil, que es el hombre, y por la muerte. 
rir humano. Es posible que en él descubramos ciertos signos que, debidamente descodificados, legitimen, de alguna manera, una nueva tesis: el hombre más allá de «estar a la muerte», es «un ser para la salvación». Para enfrentarnos con este nuevo reto, en la segunda parte de este trabajo, nos enfrentaremos críticamente con las aportaciones de algunos autores del «neomarxismo humanista» y de la Escuela de Frankfurt.

Manuel FERNÁNDEZ DEL RIESGO Profesor Titular de Filosofía del Derecho, Moral y Política. Universidad Complutense 